Research article

\title{
Modelling of mineral construction and demolition waste dynamics through a combination of geospatial and image analysis
}

\author{
Lorenc Bogoviku, Danièle Waldmann \\ Department of Engineering, Faculty of Science, Technology and Medicine, University of Luxembourg, Maison du Nombre, 6, Avenue de la Fonte, L-4369, Esch-sur-Alzette, \\ Luxembourg
}

\section{A R T I C L E I N F O}

\section{Keywords:}

Concrete recycling

Material stock quantification

Geospatial analysis

Circular economy

Construction and demolition waste (CDW)

\begin{abstract}
A B S T R A C T
As the construction sector is shifting towards circular economy models, the role of mineral construction materials as main waste fraction in terms of volumes is crucial. A characterization of this mineral stock, as well as the waste derived from it is decisive in ensuring the application of the best practices of circular economy. This paper describes a methodology for assessing the mineral building stock through a combination of geospatial and image analysis. By analysing old topographic maps, buildings are grouped according to their building age into different typologies and based on these maps the construction and demolition activity is evaluated. The mineral stock is assessed and estimations of the mineral construction and demolition waste (CDW) is generated for different stochastic scenarios. This methodology is applied exemplarily on the country of Luxembourg. It was found that the total mineral construction stock for Luxembourg is $276.75 \mathrm{Mt}$ and has been growing at a rate of $20.81 \%-$ $24.39 \%$ in the last 30 years. Furthermore, the study identified a mean age of the urban building stock of about 60 years and a typical maximum building lifetime of 122 years. Based on the stochastic projections the mineral CDW generated from the existing building stock is expected to be up to 226.9 Mt by 2100 , while if future building scenarios are considered, it can be as high as $885.3 \mathrm{Mt}$. The annual CDW production is expected to be sufficient for a viable concrete recycling activity if regulations on the waste volume flows are made available.
\end{abstract}

\section{Introduction}

Depletion of natural resources is one of the main global environmental risks. Mineral reserves show a special vulnerability in this aspect, as they are not renewable in nature. According to a recent report by the United Nations Environment (UNEP, 2019), the world's demand for sand and aggregates is recorded to be $40-50$ billion tonnes per year and projected to further increase to 60 billion tonnes per year by 2030. Over the last decades, the demand for sand and aggregates has triplicated. This increasing need has led to a worldwide shortage of inert construction materials and significant environmental effects. Riverbed corrosions, flooding, destruction of natural beaches and water pollution are only a few aspects. In Germany, an annual amount of 4.6 tonnes of sand per capita is being used (Book, 2018). Even though the mineral deposits are abundant, nowadays the majority of the natural reserves lies underneath forests, roads, railways and cities. This condition has led the German industry to seek sand extraction from the seabed, which could come with unexpected global effects on beaches and coastal cities. The effects are much more perceptible in countries with limited resource deposits and high economic growth.

On the other hand, the global generation of waste is increasing. In Europe, construction and demolition waste (CDW) is assessed to be $25-30 \%$ of the total waste, while the level of recycling is still highly variable between the member states (European-Commission). Typically, countries with a larger GDP and population density have a higher volume of demolished structures (Menegaki and Damigos, 2018). In terms of characterization of waste, the largest fraction of the generated waste is comprised of mineral fraction, where, considering the EU, approximately $90 \%$ of the waste volume is concrete waste (Deloitte, 2017), while in the US, it represents $51 \%$ of the total mass (USEPA, 2016).

This fraction, while generally treated as waste, has a significant potential in re-use and recycling (Bogas et al., 2016; Corinaldesi et al., 2011; Knaack and Kurama, 2013; Marie and Quiasrawi, 2012; Omrane et al., 2017; Sadati et al., 2016; Salesa, 2017; Yang et al., 2011) and can serve as an additional deposit of mineral resources. At the moment, the European technical standards for concrete production delineate a substitution ratio of $20 \%$ of recycled aggregates as a practical limit (BSI, 1262). To incorporate secondary raw materials in concrete production, a

\footnotetext{
* Corresponding author.

E-mail addresses: lorenc.bogoviku@uni.lu (L. Bogoviku), daniele.waldmann@uni.lu (D. Waldmann).
} 
continuous flow of material is needed due to the industrial needs of a concrete recycling plant (Ulubeyli et al., 2017) (Hiete, 2013). Furthermore, knowing the spatial distribution of the concrete stock is a significant advantage in the decision-making process of the location of such sites. Limiting the transportation distances not only reduces the carbon footprint of the recycling process, but also results in lower operational costs. On the other hand, for concrete based on recycled aggregates, the concrete production plants need to be specially regulated for each slightly different mixture, the question that arises from the industries is whether a sufficient and continuous material flow can be guaranteed to justify the investment costs of altering the production line. Although the guidelines described in the standards ensure the technical feasibility of recycled concrete, by avoiding, through a limited allowed substitution ratio, any negative influences from the recycled aggregates in the new concrete matrix, it is yet to be adopted in countries with small geographic areas. The construction industry considers it an unreachable goal given the uncertain volumes of CDW generated, which are generally perceived as too low to ensure a constant flow of materials needed for a continuous industrial production. The lack of studies and data on CDW generation and on demolition activities further increases the uncertainty of the process and the high-workload required for a full investigative record of the material stock is regarded less attractive due to the high cost/benefit ratio. Therefore, there is a dire need for a regional approach in CDW analysis for small countries to identify the scale of waste generation and to understand whether the recommended substitution ratios make sense from an economic point of view.

\subsection{Literature review}

The generation of CDW is strictly related to the service lifetime of each structure. The life expectancy of the building depends on several factors. According to EN 1990 (The European Union Per Regulation, 2002), the target lifetime ranges from 10 to 100 years depending on the type and importance of the structure. However, very rarely these conditions are determinant to the effective duration of the structure's use. In ISO 15686 (I. 59/SC 14, 1568) a factor method is used to estimate the lifetime of a building in comparison to the ideal design life. Nevertheless, the design lifetime expectancy of the building is rarely deterministic to its real survival and a more complex regional analysis must be done to take into account the economic lifetime of a structure, which can be described as the period of time where benefits of the building use surpass the costs. O'Connor (O'Connor, 2004) reports that the majority of demolished steel and concrete buildings in North America are less than 50 years old. Liu et al. (Wu et al., 2014) determines 34 years to be the average lifetime of buildings in Chongqing, China and, according to Bradley and Kohler (2007) the average lifetime of structures ranges from 120 to 300 years for Germany. The lack of consistency in the data demonstrates the need of a case-study approach in the determination of the service lifetime of buildings. Sartori et al. (Sartoriet al., 2016) used a normal cumulative distribution function to model the dynamic lifetime profile of building types in Norway divided into three main groups of 75 , 100 and 125 years. By comparing different scenarios, the study highlighted the likelihood of the large building stock remaining from the post second world war reconstruction to cause an additional increase in CDW in the second half of the century, due to the aging building stock, emphasizing the importance of the lifetime analysis of the building stock with regards to its construction period. Bradley and Kohler (2007) followed a different methodology by adopting the Kaplan-Meier procedure to model the survival rate of residential and non-residential buildings in the town of Ettlingen, Germany. The study shows that residential buildings tend to have a longer lifespan compared to non-residential structures.

Material stock analysis has been studied in several case studies (Gruen et al., 2009; Kleemann et al., 2016; Kohler and Hassler, 2002; Li et al., 2013; Ortlepp et al., 2016; Wu et al., 2014). Kleemann et al. (2017) and Heinrich et al. (Heinrich and Lang, 2019) characterized the material stock for Vienna and Munich with the aim of introducing the basis for a material database that can aid the shift towards a circular economy model for buildings. Gruen et al. (2009) introduced a methodology for creating 3D models of city areas through a semi-automated procedure, emphasizing the necessity for deeper research in the building stock. Mastrucci et al. (2014) combined a GIS environment with statistical datasets to aid the regulation of energy-saving retrofitting methods for the city of Rotterdam. The application of GIS as a medium for waste management has been first used by Jensen and Christensen in 1986 (Jensen and Christensen, 1986) to determine potential storage sites for industrial waste. Since then, the popularity of GIS as a medium for environmental studies has soared. Gallardo et al. (2014) used GIS to obtain city maps for municipal solid waste generation areas. Blengini (Blengini and Garbarino, 2010) and Mastrucci (Mastrucci et al., 2017) combined GIS-based material stock characterization with LCA as an aid to construction and demolition waste (CDW) management in an urban scale. CDW management through a GIS platform with the aim of facilitating recycling of the mineral fraction of the waste was also studied by Wu et (Wu et al., 2016). al for the city of Shenzhen in China. 1.2. Motivation of the study.

The described approaches rely heavily on building data collections as a base for analysis of the material quantification and subsequently for the assessment of waste flows. While collecting building data, such as typologies, material composition and demolition data throughout a large timeframe yields results of high precision, it is not always a feasible approach. The data on building composition are strictly protected by privacy safeguard regulations and historic records on building demolitions are not always documented. Manual extraction of this information requires not only a high amount of workload, but also a substantial amount of time, since the typical lifetime for buildings is between 10 and 100 years (The European Union Per Regulation, 2002) without considering human, economic and environmental factors which can furthermore influence the lifetime (I. 59/SC 14, 1568). Moreover, such approaches do not fully address the issue of availability of secondary raw materials as products of an industrial recycling process in areas with limited urbanization. This perspective leaves a significant gap on the evaluation of the feasibility of recycling as a viable option for the reuse of mineral CDW. In this paper, an alternative approach is presented, relying strictly on local open source data and statistical records to estimate the expected flows of mineral CDW. The use of official open-source information makes this approach significantly faster, compared to a case-study technique, and openly accessible, since the source data is not bound to control mechanisms such as copyright or patents. Furthermore, the identification of the building age, as well as of the demolition behaviour are neither based on a generalized mathematical model (i.e. building lifetime models as used in (Sartoriet al., 2016)) nor on survival analysis based on sample building population (as used in (Bradley and Kohler, 2007)) and also neither on manual extraction of data. In the present paper, an alternative method based on an automatic extraction of the building construction age is used. This method offers a global approach based on the specific studied geographic area, therefore, offering a personalized approach that can specifically consider the local aspects of each region.

The aim of the study is to propose an analysis tool for strategic decision-making in CDW management. The availability of such a methodology is crucial in asserting critical data regarding the waste volume generation and thus enabling $\mathrm{CDW}$ recycling as a viable economic activity. Moreover, the implementation of geo-spatial methods, offers an additional analysis dimension that can be used for executive decisions on the location of treatment facilities and minimization of transportation distances. This method can be particularly useful in countries or cities with limited geographical areas where CDW recycling is judged inefficient due to the relatively low population, as well as in areas where the financial means for excessive manual surveying are lacking. The proposed procedure is tested on a case study for the country of Luxembourg. 


\section{Methods}

The conceptual overview of the process is shown on Fig. 1. The procedure includes five distinct steps:
1. Spatial analysis
2. Age analysis
3. Material analysis
4. Mineral CDW flows
5. Future projections of mineral $\mathrm{CDW}$

\subsection{Spatial analysis}

The spatial analysis is fully completed in a GIS environment. In the present study, the software QGIS (QGIS) is utilized. The initial basic input at this stage consists of georeferenced shapefiles consisting of a polygonal representation of the buildings and height measurements of the built environment. One of the most popular height measurement techniques is Lidar (Laser Imaging Detection and Ranging) which yields two sets of outcome cloud points: a digital terrain model (DTM) which models the height information of the terrain only and a digital surface model (DSM) which models the height information of the elevated features, such as buildings and vegetation. An example of the DTM, DSM and shapefiles are shown on Fig. 2. Through a mathematical subtraction between the cloud points of the DSM and DTM, the height values of the buildings can be extracted and incorporated into the building shapefiles. In cases where Lidar measurements are not available, the height information can be assigned to each building through other surveying methods such as leveling, GPS measurements or terrestrial laser scanning. These methods, however, are more time-consuming and require individual measurements for each building.

\subsection{Age analysis}

Determining the construction age of the building stock is a challenging task, but it is central in determining the potential CDW flow of a region, considering the fact that the older the building, the higher the demolition potential. The material utilization is closely linked to the construction period of the building therefore, the age of the building is a strong influencing factor on its material composition. Furthermore, by relating the construction period of each building to its geographic location it is possible to generate maps of potential waste generation and offer a significant aid to waste management and treatment. However, recordings and cadastral inventories, rarely contain accessible

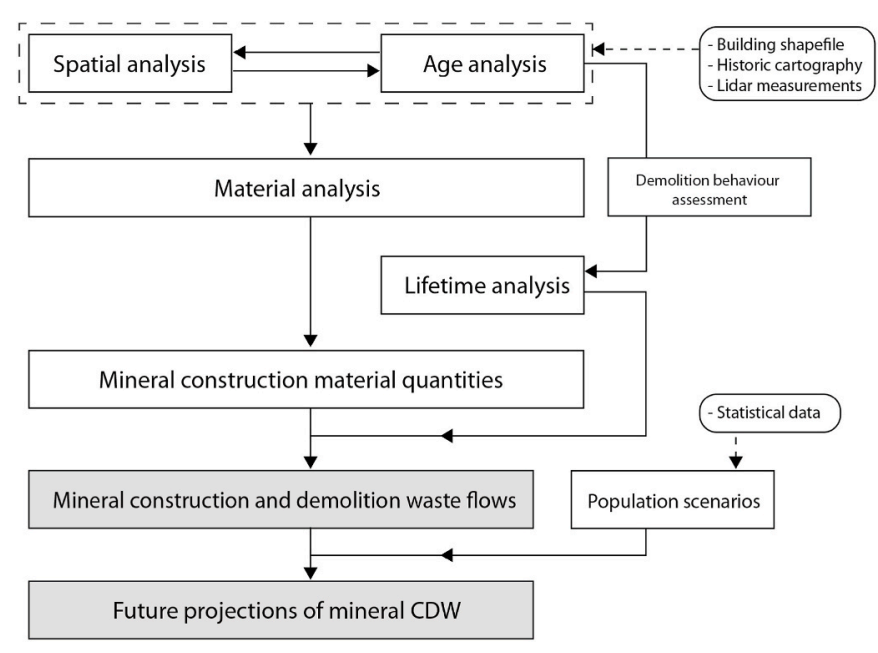

Fig. 1. General procedure.

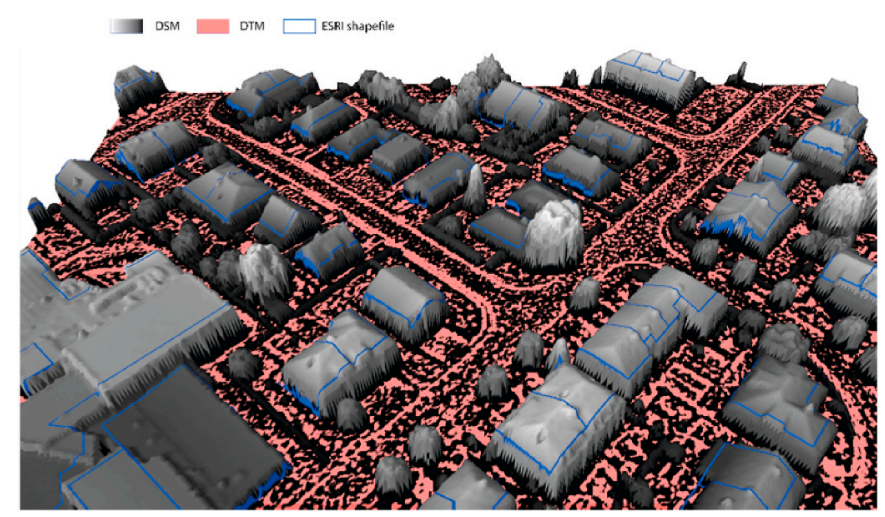

Fig. 2. Example showing the 3D representation of the DSM, DTM and building shapefiles.

information on the construction period.

In this paper, an alternative methodology based on historic maps is used (Fig. 3).

The process is based on an image analysis of the rasters derived from historic topographic maps. First, a set of maps covering the entire analysed period is to be chosen from the local cadastre administration (Fig. 3a). The maps must be of high quality and small-scale maps must be avoided, as they do not offer enough detail in building representation. Each map is analysed individually, and the range of the RGB (red, green and blue) band values is manually registered for the pixels representing buildings (Fig. 3b). For old maps, the buildings are generally represented in a single colour, therefore the range of the RGB bands is quite narrow. The colour scheme might vary from map to map; therefore, no generic range can be postulated. Therefore, a case-study approach depending on the given cartography is necessary at this step. For the selected RGB band values, a conditional is placed to assign values of " 1 " (white) for the pixels where the selected values are present and " 0 " (black) where it is missing (Fig. 3c). At this stage, however, it cannot be concluded that each pixel corresponds to the presence of a building. Depending on the colour scheme of the topographic map, the pixel values can also represent other objects, such as streets, trees or even map annotations. To overcome this, a combination between the black-and-white raster images and the shapefile polygons must be done to assess whether in any given polygon a building was present at each given time (Fig. $3 \mathrm{~d}$ and e). This results in a logical [ $\mathrm{N} \mathrm{x} \mathrm{d}$ ] matrix, where $\mathrm{N}$ is the total number of buildings present as polygons and $\mathrm{d}$ is the number of analysed maps (Fig. 3f). Using this matrix, significant information on each building's lifetime can be extracted. An example of this principle is shown on Fig. 4. If the difference between two adjacent matrix entries is negative $(0-1=-1)$, it represents the demolition of a structure during the period that the last index represents. If the difference is positive $(1-0=1)$, it represents a new construction. The construction time period of the structure is defined by using the latest string of " 0 " differences.

Furthermore, by combining the demolition trend of the total building stock over the entire period, a typical lifetime curve can be obtained. This curve can be used to show when buildings are typically demolished in the studied area and to describe a mathematical relation between the building age and its demolition likelihood.

\subsection{Material analysis and mineral CDW flow}

The mineral construction material is generally composed of four parts: the slabs, outer walls, inner walls and basements (equation (1.1)). In the present study, the construction material volumes used for infrastructure works, such as roads, sewage and various public furniture are not considered.

The material weight of the slabs can be calculated through equation (1.2). The formula considers a floor height ( $h_{\text {level }}$ ) and considers the 


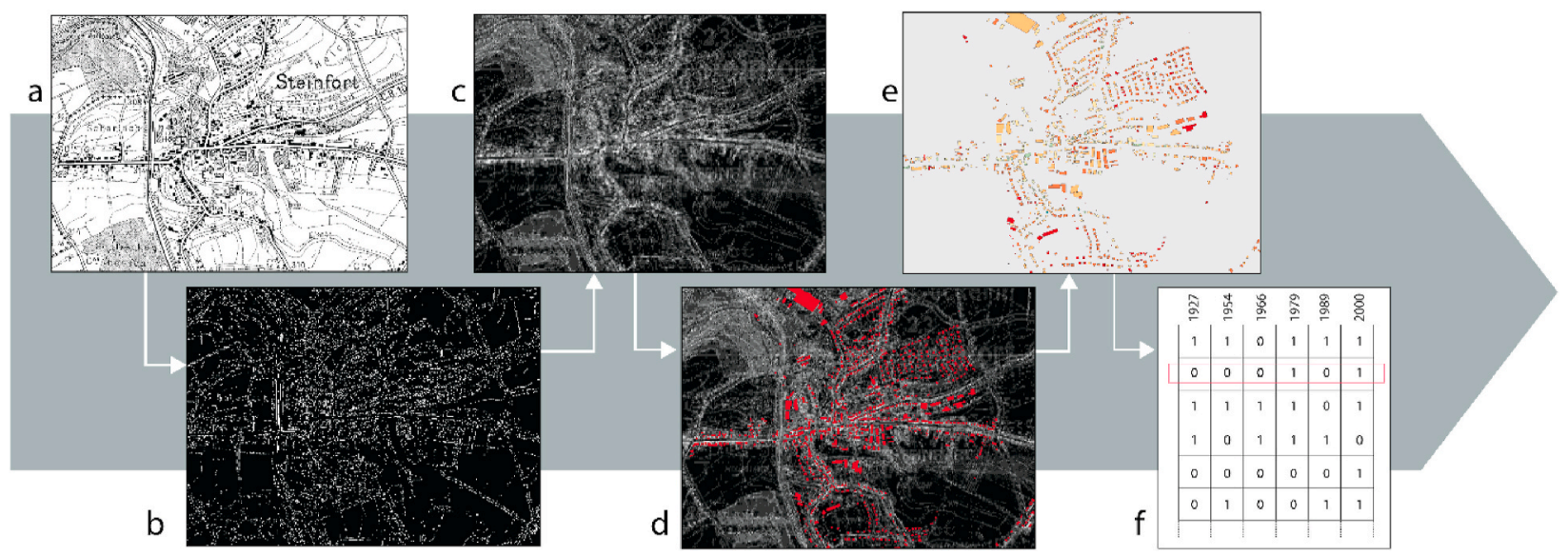

Fig. 3. Age analysis of the building stock, example of the town Steinfort, Luxembourg analysed in QGIS.
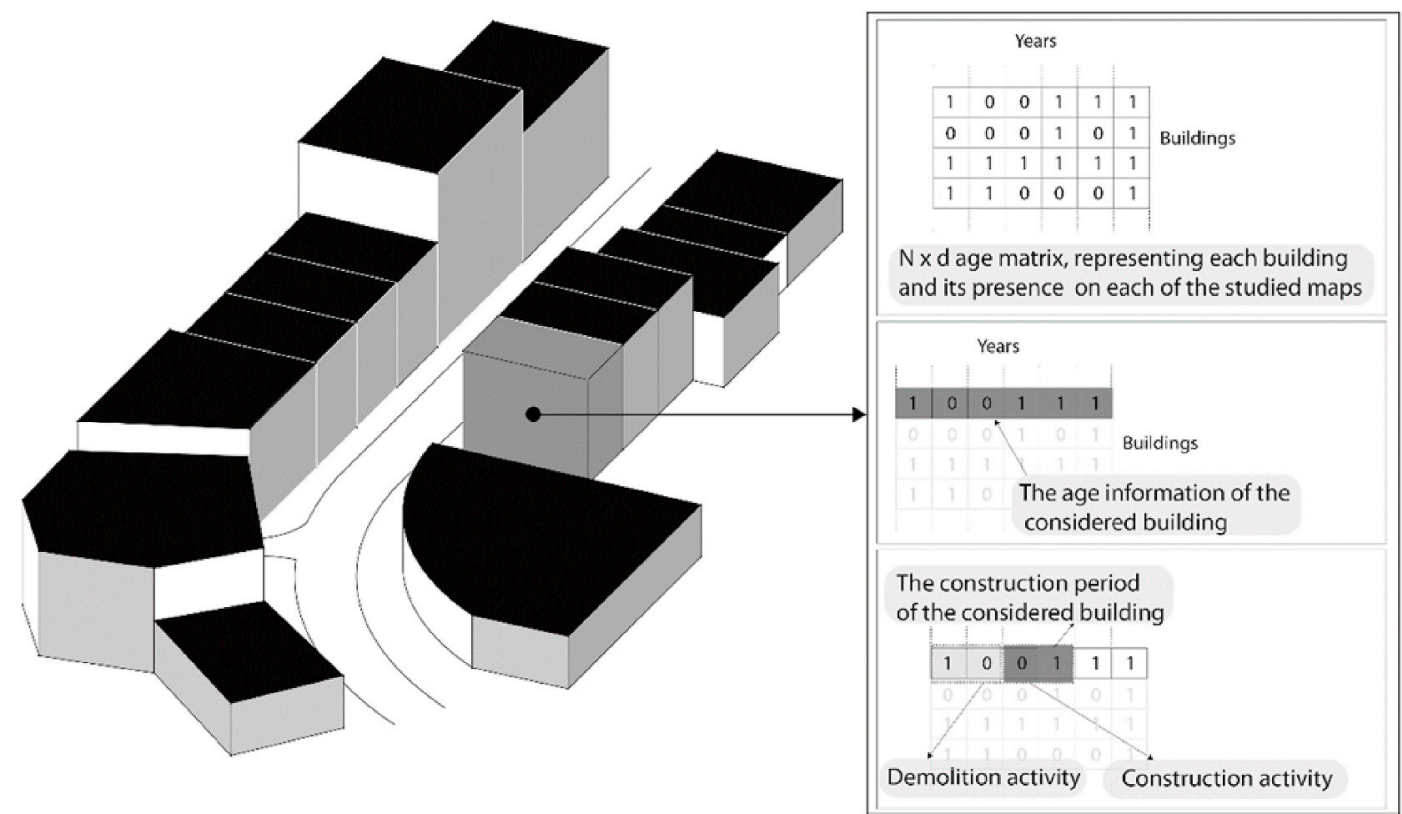

Fig. 4. Example of the age matrix of a building.

potential presence of pitched roofs, which reduces the presence of mineral material due to the slabs, since pitched roofs are typically constructed with lighter materials, such as timber.

The outer walls (equation (1.3)) are considered through the perimeter of the building, their height, and the wall thickness. The opening coefficient considers a reduction of materials due to windows and doors. It is used in combination to the age coefficient, which reflects the fact that the openings are influenced by the construction period. For example, the development of improved glazing systems allows for much wider openings without significant energy losses.

The inner walls are distinguished between structural (s) and nonstructural (ns) ones (equation (1.4)). The non-structural inner walls are thinner and have more openings. Their area has been distinguished through the useful area coefficient, which is a general real estate terminology to assess the net surface of a building excluding the walls. By using this coefficient in multiplication to the total area and reducing the known area of the outer walls, it is possible to extract the area of the inner walls (Equation (1.4a)). On the other hand, the weight of the inner bearing walls considers the structural ability of the bearing system to include an economically viable maximum span between each bearing element through the number of the inner structural walls (equation (1.4b)). This is done by assigning a typical mean span between the bearing elements $\left(l_{a}\right)$ and running the simple logical condition to determine the number of inner bearing elements $\left(\mathrm{n}_{\mathrm{ibw}}\right)$ :

if $\sqrt{A}>l_{a} ; \quad n_{i b w}^{i} \approx: \frac{\sqrt{A}}{l_{a}}$

else; $\quad n_{i b w}^{i}=0$

The value for $l_{\mathrm{a}}$ is kept constant throughout the analysis, but can vary slightly depending on the considered geographical area.

Finally, the basement is only considered through the perimeter of the building and a typical basement height, which is taken in relation to the total height of the building.

$$
\begin{aligned}
& W_{\text {concrete }}=\sum W_{\text {slabs }}+\sum W_{\text {outerwalls }}+\sum W_{\text {innerwalls }}+\sum W_{\text {basements }} \\
& \sum W_{\text {slabs }}=\sum_{i=1}^{N}\left[A \cdot d_{s} \cdot \frac{h_{m}}{h_{\text {level }}} \cdot \rho \cdot c_{r}\right]
\end{aligned}
$$




$$
\begin{aligned}
& \sum W_{\text {outerwalls }}=\sum_{i=1}^{N}\left[p \cdot t \cdot h_{m} \cdot c_{o p} \cdot \rho \cdot c_{a}\right] \\
& \sum W_{\text {innerwalls }}=W_{\text {innerwalls }}^{n s}+W_{\text {innerwalls }}^{s} \\
& W_{\text {innerwalls }}^{\text {ns }}=\sum_{i=1}^{N}\left[\left[A-\left(c_{u} \cdot A\right)-A_{\text {outerwalls }}\right] \cdot h_{m} \cdot c_{\text {opi }} \cdot \rho\right] \\
& W_{\text {innerwalls }}^{s}=\sum_{i=1}^{N}\left[n_{i b w} \cdot \sqrt{A} \cdot h_{m} \cdot c_{a} \cdot t \cdot \rho\right] \\
& \sum W_{\text {basements }}=\sum_{i=1}^{N}\left[p \cdot t \cdot h_{b} \cdot \rho\right]
\end{aligned}
$$

Where:

$\mathrm{W}$ - the weight of the element; A - area of the construction plot; $d_{\mathrm{s}}-$ depth of the slab; $h_{m}$ - mean building height; $h_{\text {level }}$ - mean floor height; $\rho$ - density; $\mathrm{c}_{\mathrm{r}}$ - roof coefficient; $\mathrm{p}$ - perimeter of the construction plot; $\mathrm{t}$ thickness of walls; $c_{o p}$ - opening coefficient; $c_{a}$ - age coefficient; $c_{u}-$ useful area coefficient; $c_{o p i}-$ inner opening coefficient; $n_{i b w}-$ number of inner bearing walls; $h_{b}-$ height of the basement.

The calculated material weights are fed into the GIS software, relating each material quantity to the polygonal representation of the buildings, resulting in a spatial distribution of the material quantities.

The mineral CDW can be defined to be equal to the demolished mineral construction. Therefore, the flow of CDW can be extracted by combining the lifetime curve and the material stock calculated for each structure through equation (1.1).

\subsection{Future projection of mineral CDW flows}

Finally, to estimate future amounts of mineral CDW, a statistical outlook must be done. The number of buildings to be constructed in the future will be proportional to the population and the required living area per capita is unlikely to be change significantly in the near future. Therefore, at this stage, two steps are foreseen:

1. Determination of the future construction volumes

2. Estimation of the waste arising

To estimate the future construction volumes, a relation between the weight of construction material to the population can be extracted from the population records and the material stock quantification discussed in the previous section. Using this ratio and the expected population growth, a future projection of the potentially used construction material can be made. Furthermore, by using the previously obtained lifetime curves of buildings, it is possible to extract the expected CDW arising from the considered stochastic scenario.

\section{Case study}

This section presents the application of the described procedure for the country of Luxembourg, as an example of a small country with a combination of few highly urbanised areas and a majority of rural regions. The application of the material stock analysis in the context of geographically small areas will yield important feedback on the volumes of the mineral construction waste arising in similar regions and will be of significant help in steering the management of CDW in quantitative terms. Moreover, it will be crucial in answering the question on whether concrete recycling is a feasible option for the limited mineral CDW in such areas.

Luxembourg currently records a population of 626108 inhabitants, with an average density of 242 habitants per $\mathrm{km}^{2}$ (The Statistics Portal of Luxembourg). The local construction industry has generated a $33.9 \%$ investment increase in the period after the 2008 crisis (European Construction Sector Observatory, 2017) and in the period from 2013 to 2017 , there is a $39 \%$ increase in the built volume in the country (The Statistics Portal of Luxembourg). The generation of mineral waste accounts for over $95 \%$ of the total national generated waste. In 2014 , the amount of mineral waste was $0.57 \mathrm{Mt}$, resulting in 1.04 tonnes of construction and demolition waste (CDW) per capita (Villoria Sáez and Osmani, 2019). Even though the majority of the CDW is re-used, nearly all its volume is backfilled (European-Commission). Moreover, recordings of waste streams in the country are not applied, which makes it difficult to trace the origin of the waste and to have a reliable recorded amount of CDW. Private companies operating in the demolition sites are responsible for the disposal of the waste and the majority of it never reaches the treatment plants. Despite its industrial potential, CDW is often crushed using mobile plants and backfilled on site. This situation not only results in a loss of resources, but also, due to lack of data, makes it difficult to organize and design a recycling process for concrete based on the principles of circular economy.

\subsection{Geographical data collection and height analysis}

The geographic data on buildings is collected from the official open database of Luxembourg's Administration of Cadastre and Topography (Administration du cadastre et de la topographie, 2020). The building's representation comes as Esri shapefiles categorized by communal codes, which allocates buildings in 105 communes. The height information is processed through the official Lidar data of 2019 (Administration) (Fig. 5) which has a point cloud with a density of 15 points per $\mathrm{m}^{2}$ and a pixel value of $50 \times 50 \mathrm{~cm}$. The subtraction between the Digital Surface Model (DSM) and Digital Terrain model (DTM) was done in Grass QGIS, obtaining a third layer, which contains the z-dimension of manufactured objects and vegetation. Furthermore, using the zonal statistics (Zonal Statistics Plugin, 2020) in QGIS, it is possible to add the previously obtained heights to the shapefiles as a separate attribute. Since the achieved point cloud from the Lidar detects a high number of points per single building, due to the irregularities of the surface and the shape of each structure in the z-dimension (i.e. pitched roofs, chimneys, mansard roofs), the mean value of the heights has been considered in this study.

\subsection{Age analysis}

The detection of the building age is done by analysing historical topographic maps. More specifically, cartography from the years 1927, 1954, 1966, 1979, 1989 and 2000 were chosen from the collection of the Administration of Cadastre of Luxembourg. The choice of the maps was done with the aim of having clear and high definition rasters distributed over the last century as uniformly as possible. Special attention was given in assurance that the representation of the building units is clear in all maps and no colour damage exists between the different panels. The scale of the original maps was 1:20000 and 1:50000. All maps were georeferenced with the reference frame for Luxembourg: EPSG:2169, Luxembourg 1930/Gauss, which was kept constant throughout the work of this paper.

In the next step, the raster was analysed in terms of pixel count for the colour value range in which the buildings were represented. This was different for each raster, as the colour scheme of the maps was not consistent throughout the years. The pixel value range for each of the three bands of the six layers was registered manually. An operation on raster calculation, yields single band rasters with a binary code, where " 1 " represents pixels that fulfil the given condition of the pre-defined RGB bands and " 0 " represents the "empty" pixels. The analysis of the age matrix was done using a conditional loop to assess the more recent construction of the building. For every row of the matrix, a subtraction between the matrix index and its precursor was done until the difference remained 0 . The point where the index difference showed a negative value is considered to be the earlier record of the specific building in the 

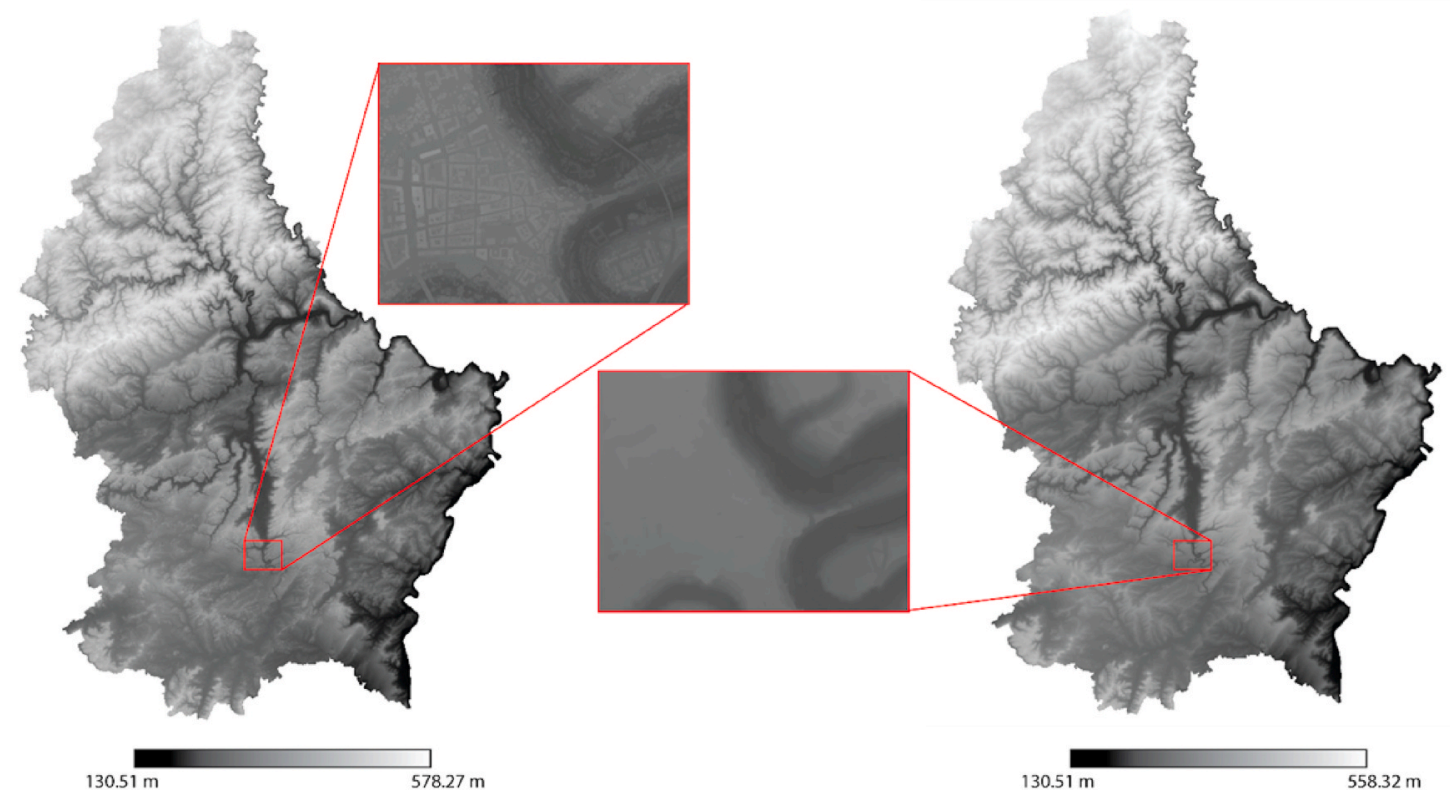

Fig. 5. Height analysis of Luxembourg using Lidar data from DSM (left) and DTM (right).

considered map set and that is considered to be the age of the building. The structures that remained unclassified were recent buildings, which do not appear in topographic maps from 1927 to 2000, therefore they were classified into an additional category of structures erected between 2000 and 2019. Finally, an age-group targeted analysis was done in order to observe the demolition dynamics of each age-group. This was again realised by analysing the age matrix to assess the total number of buildings that were demolished in every considered time period. Thus, a relation between the construction age of the structures and their survival potential is compiled.

\subsection{Building typology}

The building typology is depending on the age group and where the building is allocated. Luxembourg has a typical North-West Europe building stock, similar mostly to the western part of Germany and the north-eastern region of France. In the buildings of the beginning of the 20th century and earlier, a massive use of stone in the walls as a bearing element is evident. The slabs of these structures are either made of timber or concrete plates, while roofs are mostly timber frames. As in all Europe, in Luxembourg, an acceleration in built volumes is noticeable as result of the post war reconstruction, especially after 1945. In the second half of the 20th century, the use of concrete blocks and reinforced concrete has been the main technical element, particularly with the increase of building volumes. Steel structures are also present in the country, although in a number which is limited and clustered around the industrial areas of the steel industry. In the present study, the building typology has been assessed through the Tabula database (European Union, 2020) by relating to the German annex of the Tabula database. The steel structures are manually identified and excluded from the calculations.

\subsection{Assessment of the concrete volumes}

The depth of the concrete slab has been considered to be $18 \mathrm{~cm}$ uniformly in all considered age categories. This is a simplification based on the technology of reinforced concrete, which throughout the years has not significantly affected the depth of the slabs. The opening for stairs is not considered as reduction into volume, as the concrete volume resulting from the staircase is comparable to the volume of the opening. The roof coefficient considers the presence of a timber roof. In the case of the building stock of 1927, all structures are considered of having a timber roof which leads to the definition of the roof coefficient to be equal to 0.66 , while on all other cases, it is 1 .

In terms of bearing walls, there are two types: masonry walls (buildings 1927 and before) and concrete or concrete masonry walls (1954 and after). The thickness of the outer walls is considered to be 25 $\mathrm{cm}$. However, older buildings tend to have thicker walls on the perimeter. To take this fact into consideration, the age coefficient $\left(c_{a}\right)$ is used to double the thickness for buildings built before $1927\left(c_{a}=2\right)$ and to increase by $50 \%$ the outer wall thickness for buildings constructed between 1927 and $1954\left(c_{a}=1.5\right)$. For the other construction periods, this coefficient is taken equal to 1 . The coefficient for the openings on the outer walls $\left(\mathrm{c}_{\mathrm{op}}\right)$ are taken as 0.95 for the construction period 1927-1954; 0.85 for the construction period 1966-1979; 0.75 for the buildings constructed in 1989 and 0.7 for the buildings constructed after 2000. More modern buildings tend to have larger openings on the façade; therefore, the coefficient takes lower values for more recent buildings.

The volume of inner walls is considered through the useful coefficient $c_{u}$, which is taken as 0.75 (STATEC, 2020). The inner opening coefficient $\left(\mathrm{c}_{\mathrm{opi}}\right)$ considers all the internal openings for doors and is taken as 0.90 . The internal bearing walls are considered through the number of inner bearing walls $\left(\mathrm{n}_{\mathrm{ibw}}\right.$ ) which takes into consideration the structural need for bearing elements at a given horizontal distance. In the present study, the maximum distance without bearing elements $\left(l_{a}\right)$ is considered to be $4 \mathrm{~m}$. The depth of the basement is considered as $1 / 3$ of the mean height of the building, which is an assumption based on the static height of the structure. An overview of the used parameters is shown on Table 1.

Table 1

Parameters used for defining the weight of mineral building materials in the studied building stock.

\begin{tabular}{|c|c|c|c|c|c|c|c|}
\hline \multirow[t]{2}{*}{ Construction year } & \multicolumn{2}{|l|}{ Slabs } & \multicolumn{3}{|c|}{ Outer walls } & \multicolumn{2}{|c|}{ Inner walls } \\
\hline & $\mathrm{t}[\mathrm{cm}]$ & $c_{r}$ & $\mathrm{t}[\mathrm{cm}]$ & $\mathrm{c}_{\mathrm{op}}$ & $\mathrm{c}_{\mathrm{a}}$ & $\mathrm{c}_{\mathrm{u}}$ & $\mathrm{c}_{\mathrm{opi}}$ \\
\hline 1927 & 18 & 0.66 & 25 & 0.95 & 2 & 0.75 & 0.9 \\
\hline 1954 & 18 & 1 & 25 & 0.95 & 1.5 & 0.75 & 0.9 \\
\hline 1966-1979 & 18 & 1 & 25 & 0.85 & 1 & 0.75 & 0.9 \\
\hline 1989 & 18 & 1 & 25 & 0.75 & 1 & 0.75 & 0.9 \\
\hline$>2000$ & 18 & 1 & 25 & 0.7 & 1 & 0.75 & 0.9 \\
\hline
\end{tabular}




\section{Results}

\subsection{Geographical data collection and height analysis}

The height profile (Fig. 6) shows that the country is characterized by relatively small buildings in terms of area and height. The mean height is $6.66 \mathrm{~m}$, while the mean building area is $175.25 \mathrm{~m}^{2}$. In addition, it is of interest to analyse the spatial distribution of the buildings' characteristics on a country-scale (Fig. 7). The spatial distribution in terms of mean building height is heterogeneous within the 105 communes of the country, although there is a visible peak in the central and south-western areas. In the City of Luxembourg, the peak is due to the large urbanization scale, which includes several high-rise buildings. For the commune of Esch-sur-Alzette (south-west), there is a high presence of industrial buildings. In terms of the building area (Fig. 7b), the country shows a different trend which is more heterogeneous. The northern region is characterized of buildings with larger areas, which is mostly due to agricultural structures. The percentage of built area ranges from $0.09 \%$ to $12 \%$ with the south-western area resulting the most utilized area in the country in regard to construction.

\subsection{Age analysis}

The age matrix for the country of Luxembourg is shown on Fig. 8. The grey colour represents the recognition of a building's presence on the considered map, while the white colour shows the absence. The subsequent change of colours from grey to white is defined as demolition.

From the age analysis, a characterization of the building stock based on the construction age can be made (Fig. 9). The building stock in Luxembourg can be considered mixed in terms of age. A significant amount of structures was constructed before 1927 (31.30\%). This includes the historic centres of the cities, but also the major industrial structures which were erected prior to 1927 . At the beginning of the 20th century, Luxembourg was one of the largest steel producers in Europe due to the iron mineral deposits in the south of the country. At this time, there was a surge in construction of industrial structures and habitation for the growing population of workers. This is mostly noticeable in the south-western cities (e.g. Esch-sur-Alzette, Differdange, Dudelange). After the second World War, the reconstruction process caused an increasing trend leading to the construction of mainly residential structures. Following a normalization period between 1966 and 1979, the numbers are currently on a constant rise.

In terms of building use (Fig. 9b), the total gross volume is comprised majorly of residential buildings. The construction of new industrial and public buildings has experienced a surge in the last 30 years. In the period $1989-2000$ there is a $507 \%$ increase in gross volume of industrial buildings compared to the previous time period. This is accompanied by

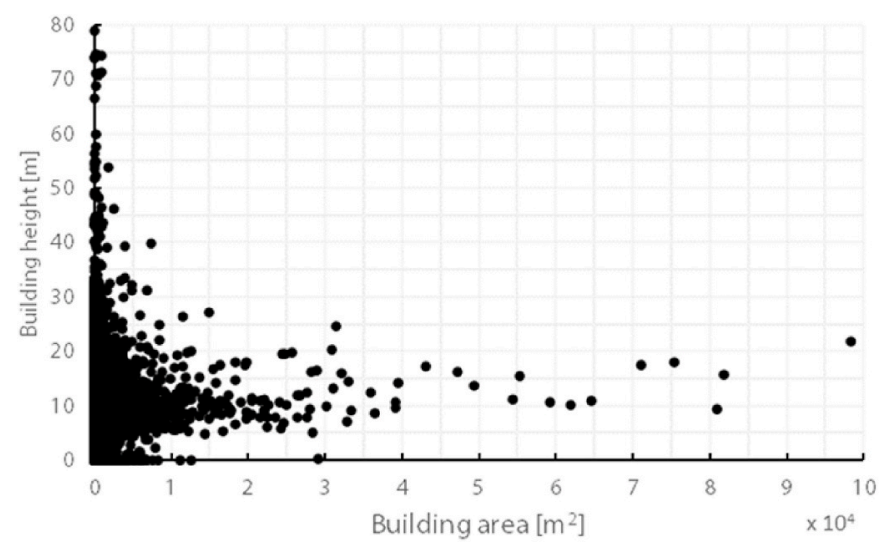

Fig. 6. Height profile of the country showing the relation of each building area to its height. a further $21.9 \%$ increase of the industrial gross volume built in the last 20 years.

The mean building age per commune (Fig. 10) gives an outlook on the potentiality of waste production. The oldest building stock is located in the south-central area, where Luxembourg city is located and in the south western area, where the cities of Esch-sur-Alzette, Differdange and Dudelange are located. These cities constitute $32 \%$ of the total population of the country and have a population density which is 2.99-9.91 times higher than the national average density. Therefore, not only these areas are older in terms of their built environment, but they are also expected to have a larger concrete stock, resulting in a higher potentiality for CDW production.

According to official data from the Luxembourg Portal of Statistics (STATEC) (STATEC, 2020), for the period 1979-2017, there was a mean increase of 1.04 in the number of buildings constructed every year, while for the calculated model, this factor is 1.16 . This difference is due to the nature of the data, which for the calculated model is accumulative in a clustered way of 10-20 years rather than recorded on a yearly basis, while for the statistical data, it comes from annual recordings. Additionally, the shapefiles that are used for calculating the building volumes in QGIS do not always perfectly correspond to the definition of built structure in statistical records.

\subsection{Assessment of the concrete volumes}

According to the analysed model (Fig. 9), the current concrete stock in Luxembourg is $276.75 \mathrm{Mt}$. It accounts for 450.817 tons/capita considering the country's population of 613894 inhabitants. The ammount of concrete stock has been growing at a rate which ranges from $20.81 \%$ to $24.39 \%$ in the last 30 years. It can be noticed that the concrete stock produced after 1979 accounts for more than half (52.84\%) of the total, while the concrete stock remaining from before 1979 is mainly part of buildings which existed before 1927. This hints at a significant lack of remaining constructions from the building stock of the years 1954-1979. It can be due to several aspects. First, the World War 2 has greatly influenced the construction industry in Europe. The rapid reconstruction of the post-war era resulted in structures with a lower quality which had a major potential of depreciation. Moreover, the common use of asbesthos in structures constructed during the 20th century may be a strong reason for their low degree of survival (Kamedaet al., 2014).

In terms of usage of materials, the residential structures constitute the majority of the share in almost all age groups (Fig. 11). A distinction can be made in buildings from the last 20 years, where industrial structures have peaked. This fact is quite reasonable considering Luxembourg's soaring economy of the last years (Hardiman, 2018) (La Chambre de Commerce du Luxembourg, 2017) (The Statistics Portal of Luxembourg, 2020).

\subsection{Demolition behaviour and assessment of future volumes of concrete}

The global survival of each building stock in relation to its construction age is shown on Fig. 12. It shows that the survival of each building is not directly linked to its age. For example, the building stock constructed before 1927 shows a higher survival ratio compared to the buildings stock constructed between 1927 and 1954, even though the former is comprised of older structures. The buildings constructed after 1989 display a higher rigidity in terms of their demolition compared to earlier structures with less than $10 \%$ of them being demolished.

In order to analyse future mineral CDW trends, a global analysis on the survival of structures needs to be made. With this aim, a regression analysis curve $\left(\mathrm{R}^{2}=0.84\right)$ is extracted from the available data, as a cumulative distribution function for the survival of the building stock (Fig. 12). By forecasting the equation to the point where the survival rate becomes 0 it is possible to assess the maximum typical lifespan of the buildings in Luxembourg from a global point of view. The typical 

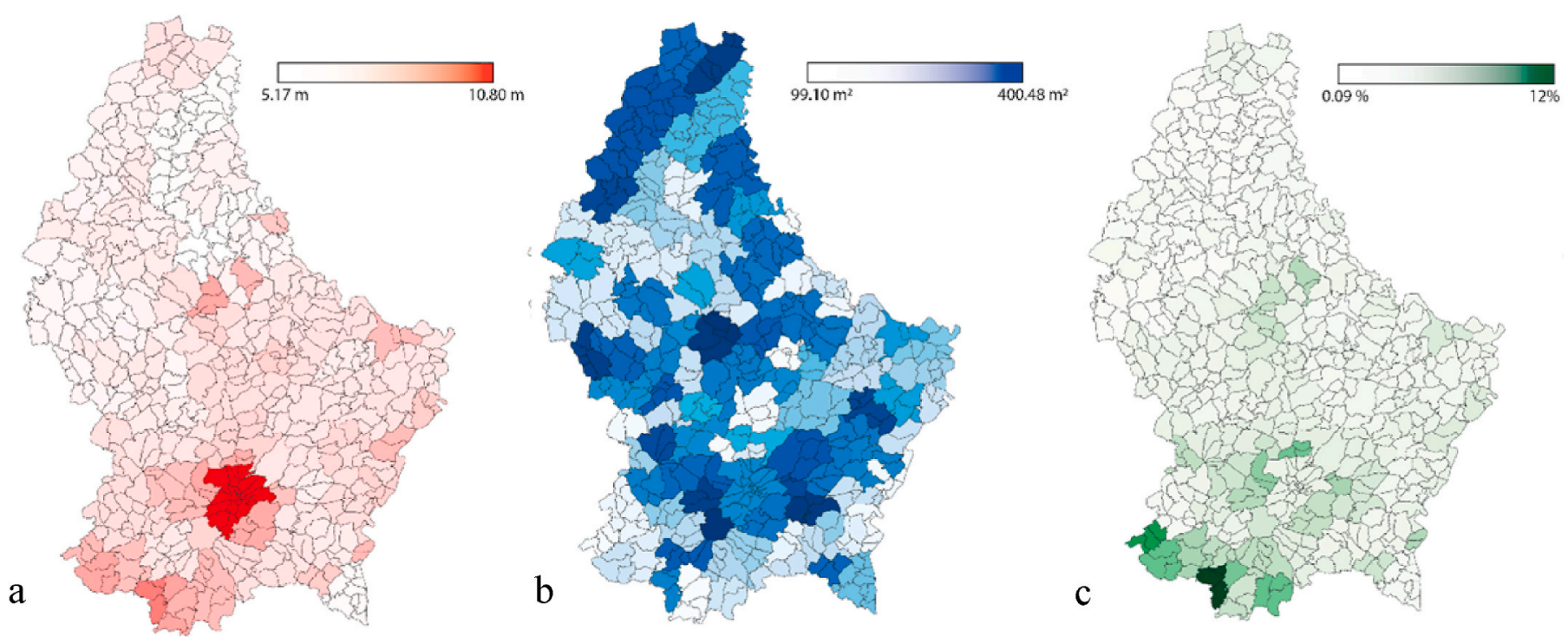

Fig. 7. Spatial analysis of the built environment in Luxembourg: a. Mean building heights; b. Mean building areas; c. Rate of built area.

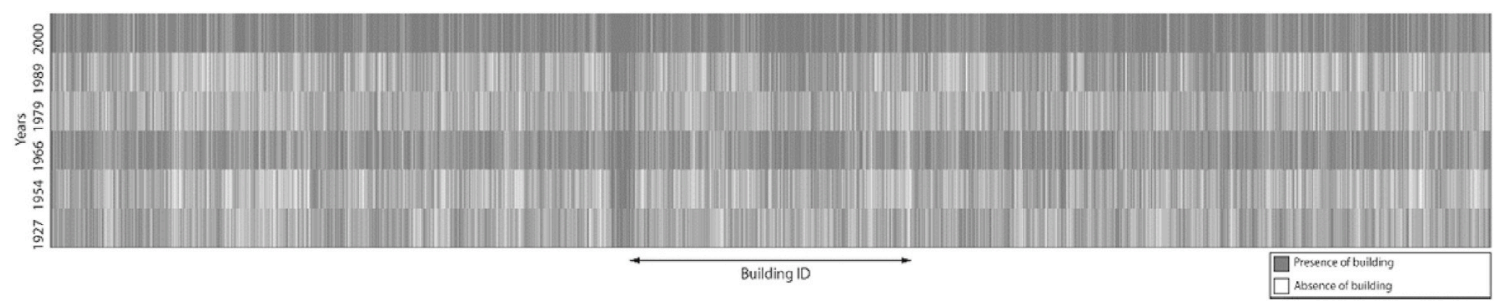

Fig. 8. Heatmap representing the age matrix for the entire building stock of Luxembourg.
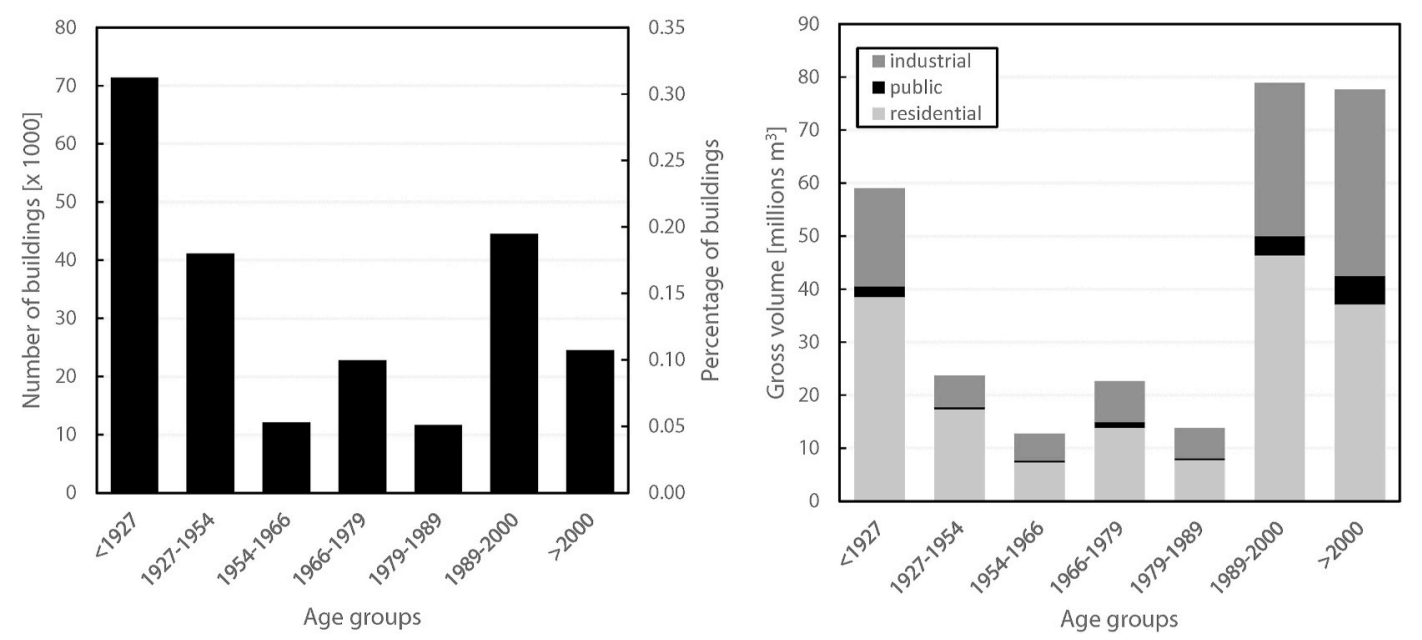

Fig. 9. Age characterization of the building stock in Luxembourg: a. Based on number of buildings; b. Based on gross volume.

lifespan of the building results to be 122 years. In the analysed map set, structures constructed before 1927 are not categorized into smaller construction age groups. This lifespan is consistent with the predicted service design lifetime of structures (The European Union Per Regulation, 2002) and falls within the range of other studies (Sartoriet al., 2016).

The cumulative distribution function for the survival of the building stock (Fig. 12) shows a significant slow-down on the demolition of structures older than 50 years. This is most likely related to their historical value of old buildings. Thus, it is very implausible for a building stock representing a specific age group to be completely demolished. Even though a meticulous limitation on the extrapolation of survival function remains difficult, in this study a $10 \%$ of the existing building stock is considered within this category, while for future stock, it was increased to $30 \%$. The reason behind this lies in the quality of construction materials used nowadays, which are expected to have longer lifespans and receive lower levels of devaluation. Furthermore, considering the national plan for Luxembourg regarding the energetic performance of buildings (Reding et al., 2016), it is projected that new structures will have better conditions in terms of inhabitant well-being 


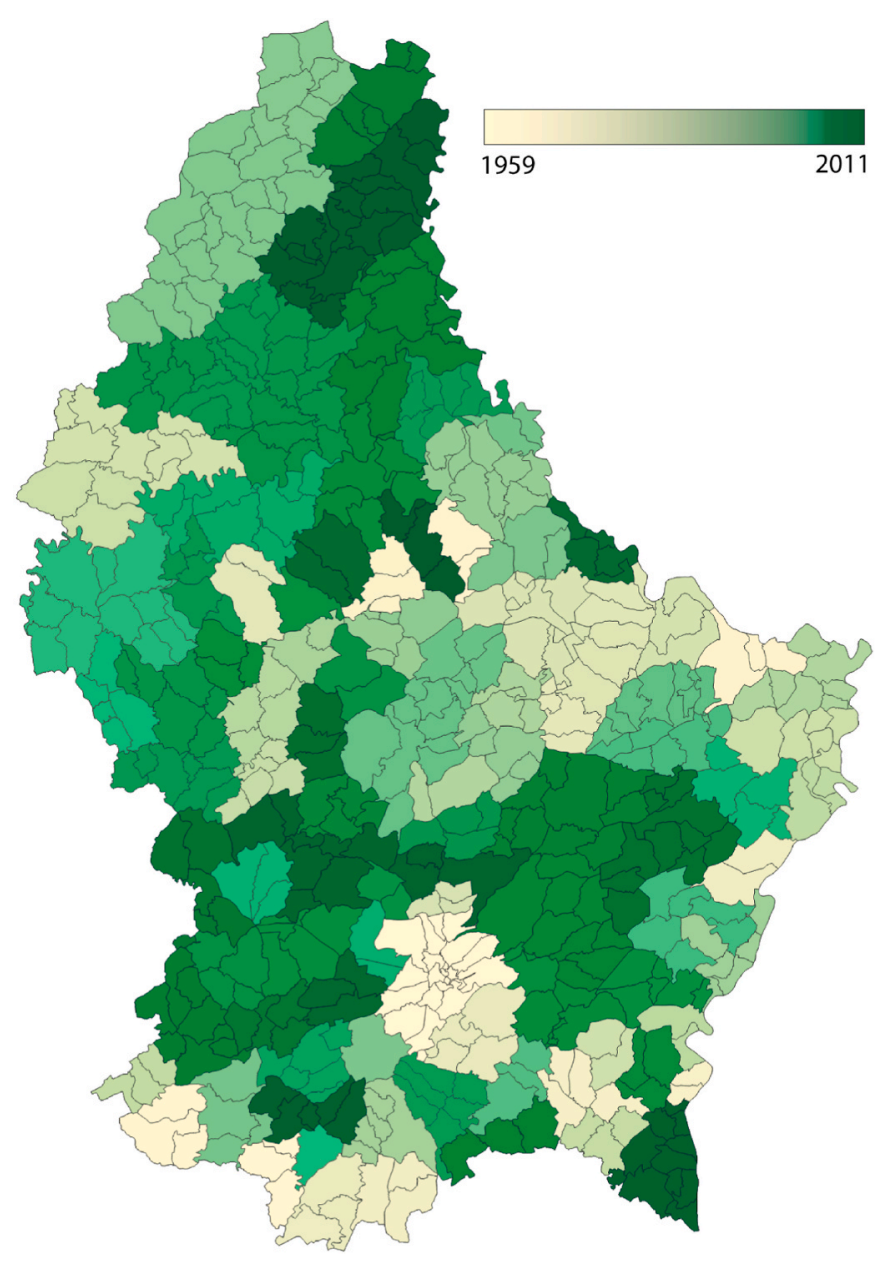

Fig. 10. Mean age for each communal division in Luxembourg.

as well as economic performance. Additionally, the use of cladding and thermic insulations will result in a lower environmental impact for the core structural materials in the long-term. From this model, a general trend for mineral CDW generation of the country can be assessed. Two additional scenarios representing a lifetime profile of 100 years and 150 years are considered as stochastic models by changing the maximum lifetime, but preserving the general mathematical shape of the function (Fig. 12), thus creating a larger extent of consideration.

Furthermore, it is of interest to look into the demolition dynamics of each considered age-group (Fig. 13). The demolition rate is highly dependent on the historical situation in terms of economic and political situations and the demolition behaviour results to be different for each building stock depending on its construction age-group. Generally, there is a high-peak of demolished buildings approximately 30 years after their construction. This is consistent with the age-groups 1954, 1966 and 1979. For the building stock constructed before 1927 a complex demolition profile can be observed (Fig. 13a). In total, $56.68 \%$ of this building stock has been demolished (Fig. 12) until 2019 and there are two demolition peaks visible. The first one corresponds to the second World War while the second one corresponds to the shut-down of the traditional steel industry where it has been switched to a more modern process based on electric furnaces and recycled steel. Indeed, in 1994 this decision on the transition was taken, paving the way for the urbanization of these areas (Casali, 2012). This change has caused most probably a second peak in the demolition of old industrial structures, which dated back to the beginning of the 20th century. The demolition behaviour of building stocks from 1954, 1966 and 1979 (Fig. 13b, c, d) show a similar trend represented by a bell-shaped parabola. The peak of their demolition profiles shows maximum values between 1980 and 1990, which is compatible with the second demolition peak of the building stock of 1927, reinforcing the high influence of the economic conditions on the building dynamics. In contrast, the buildings from 1989 show a lower demolition profile (Fig. 10e).

The geographic distribution of concrete stock (Fig. 14) shows a concentration of the material in the central and southern part of the country. As previously discussed, these areas resulted to be not only the highest populated regions of the country, but also the communes with the oldest building stock. The high concentration of materials confirms the highest potential of these areas for future origination of mineral CDW.

The accumulative amount of mineral CDW for the present building stocks, composed of buildings of different construction ages (Fig. 15), is divided into three scenarios depending on the maximum life expectancy of the building stocks, which are based on the previously defined lifetime scenarios (Fig. 12). Each building stock is considered though its previously assigned age, therefore, depending on the lifetime curve, each age-group has a specific survival rate throughout the considered time period, resulting in a dysphasic starting point for the three different scenarios. In general, there is a higher rate of CDW generation from 2020 to 2050 and a lower intensity from 2080 to 2100 , with the 150 years scenario showing a different trend in the last part of the century. From the cumulative production curve, annual production curves are extracted in Fig. 13b through derivation of the regression lines from the graphs of Fig. 13a, making it possible to have an estimation on the annual production rate of CDW related to the current building stock. Indeed,
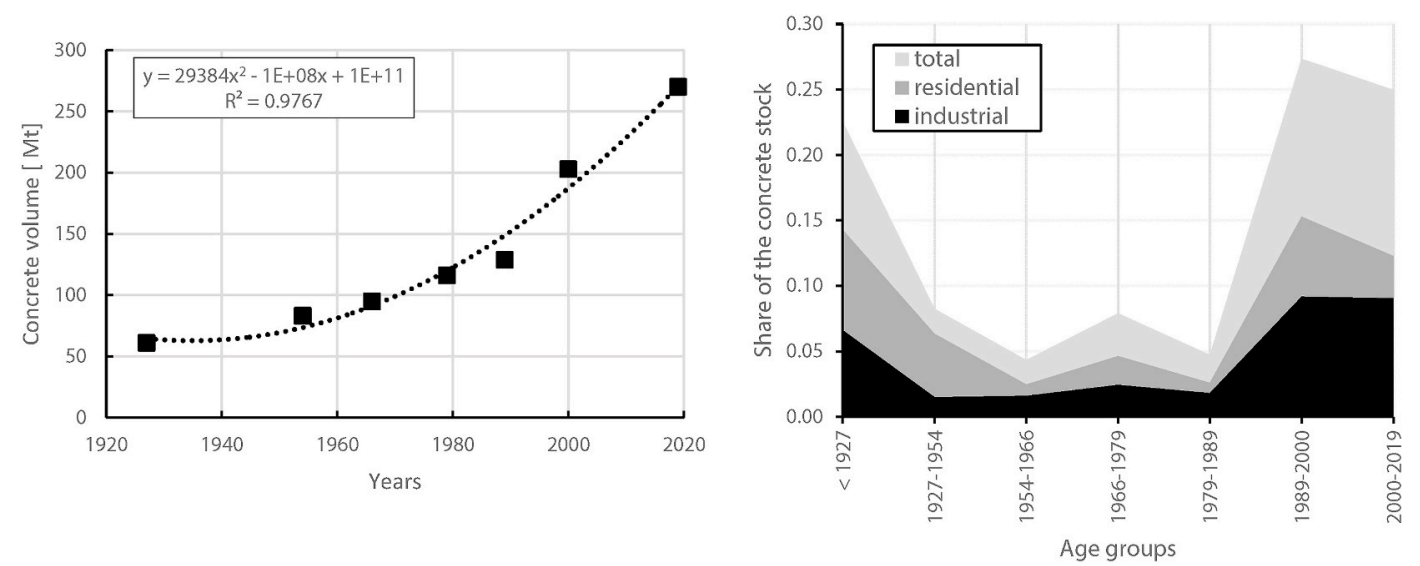

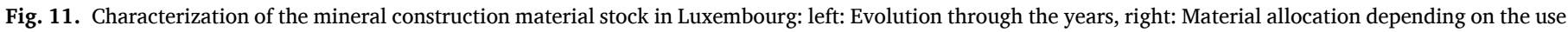
of building. 


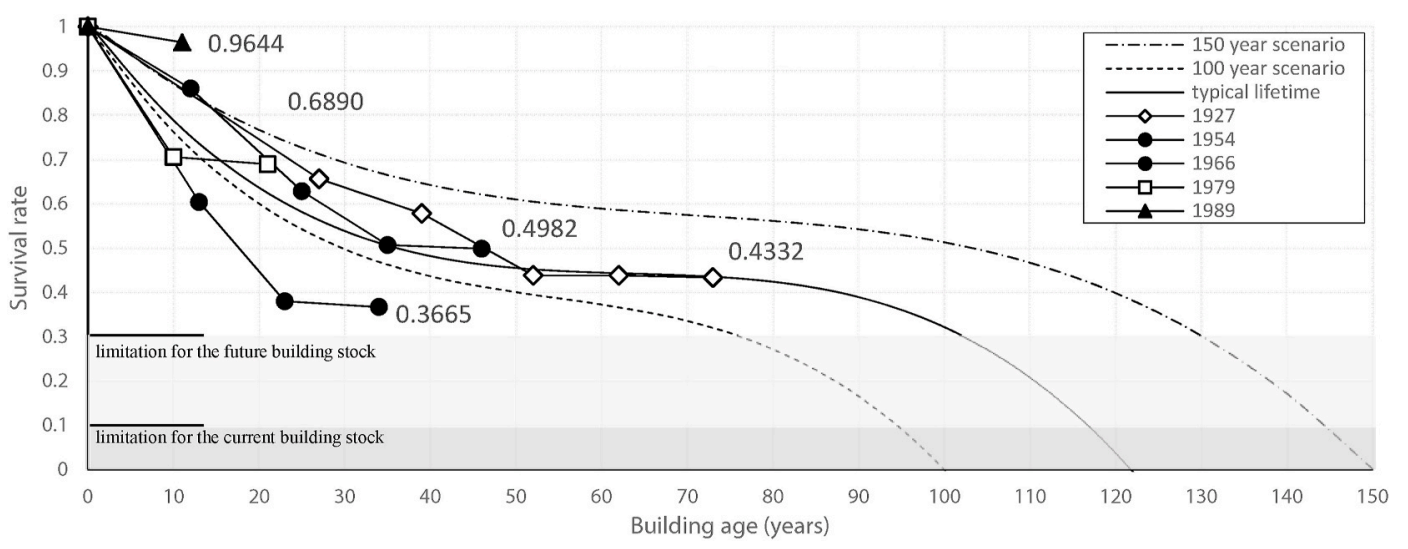

Fig. 12. Survival analysis and typical lifetime curve for buildings in Luxembourg, as well as the two additionally considered scenario.
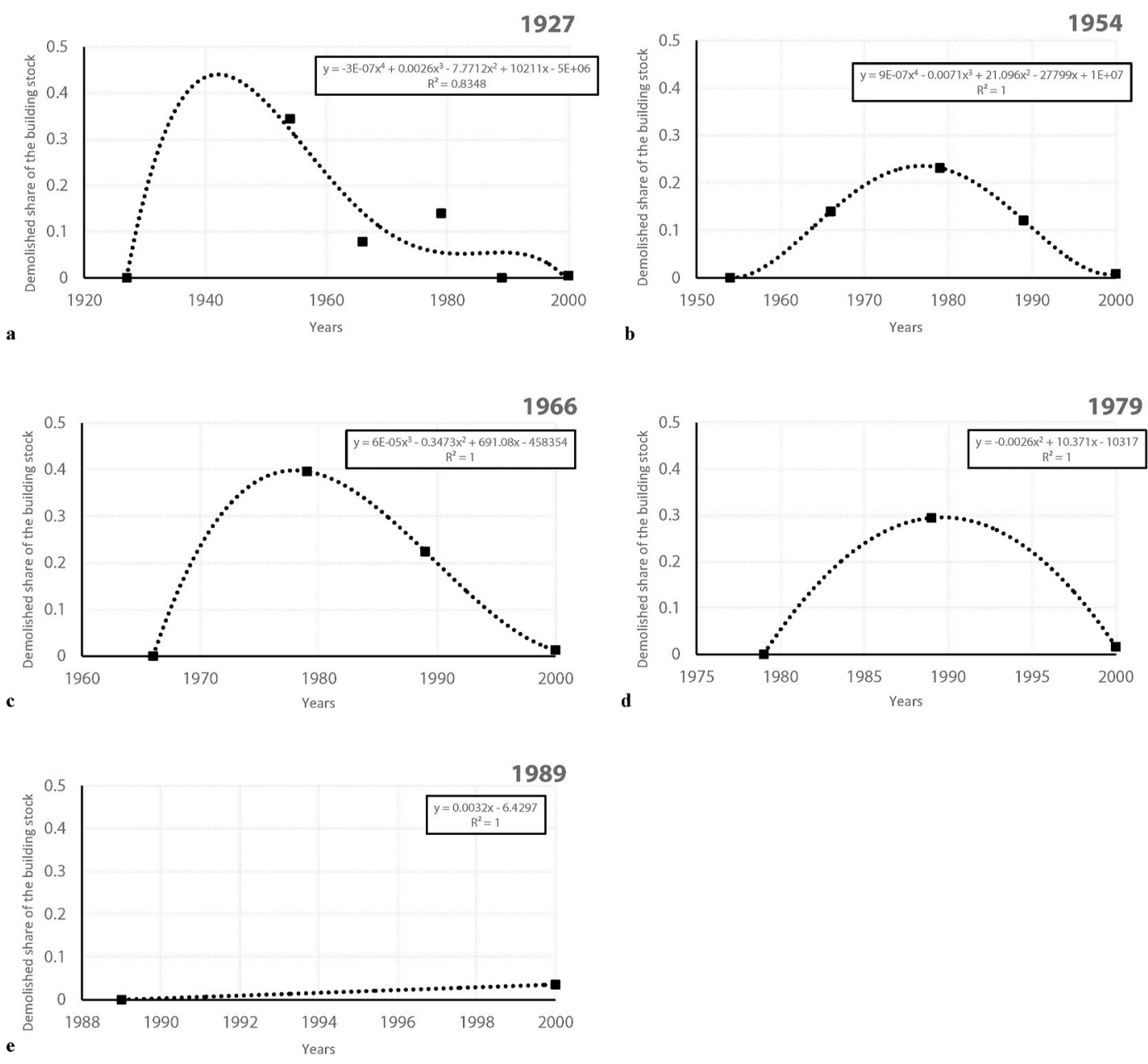

Fig. 13. Demolition profiles of different age groups.

there is a peak in the annual production related to the worst-case scenario in the period between 2020 and 2030, after that the annual production for the three scenarios fluctuates in a decreasing trend, due to the depletion of the current building stock. It can be noticed that, even without considering new construction, the annual production shows a mean of ranging from 1.38 to $1.49 \mathrm{Mt}$ /year. Except for the first and last considered decades (2020-2030 and 2090-2100), there is no significant difference in the three considered scenarios.

The future projection of the population is divided into three scenarios namely with a $1.13 \%, 0.52 \%$ and $0.17 \%$ average yearly increase rate (Fig. 16) during 80 years. The first increase rate is based on the current population growth of Luxembourg, while the others are considered to be lower. A higher scenario is not considered, due to the logistical issues that an increasing population density would cause in the country, thus making such scenarios unlikely. It is logical to think the construction as being proportional to the population, since an increase of population will lead to more demand for housing. Comparing the data from 1970 to 2020, a concrete demand per capita of 463.2 tons/capita can be extracted. This value is implausible to have a high sensitivity, since the spacing needs per person are improbable to change. Therefore, 


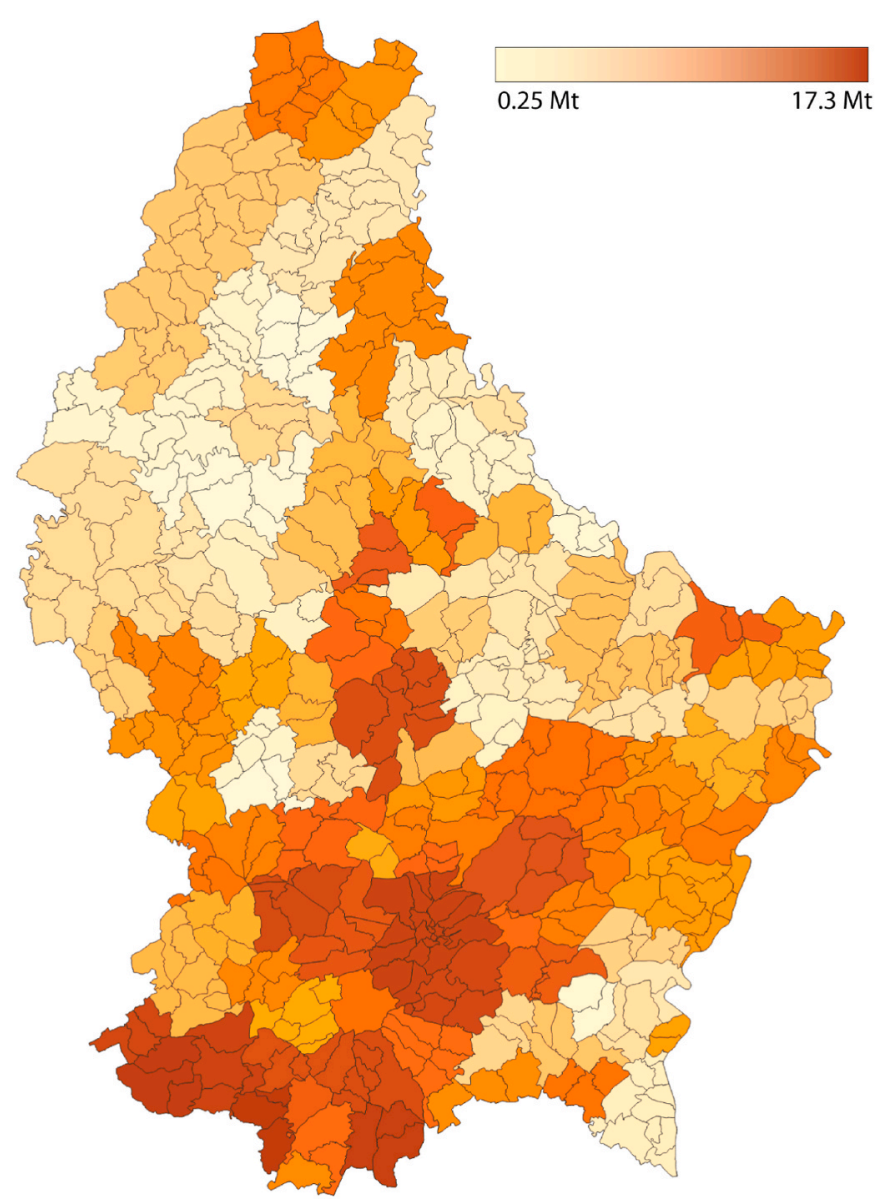

Fig. 14. Spatial distribution of the present concrete stock in Luxembourg.

the new construction generation can be directly assessed from the population scenarios and by using the lifetime curves (Fig. 12), the generation of mineral CDW can be evaluated both accumulatively and annually (Fig. 17).

The accumulative projection (Fig. 17a) shows that in the next 80 years between 890 and $638 \mathrm{Mt}$ of inert waste is expected to be generated in the country. In comparison to the data generated only from the analysis of the current building stock, the future construction will have a significantly larger influence on the country's waste stream representing $73.96 \%$ of the total inert CDW by 2100 . However, the sensitivity of the data is lower than the previously considered scenario, with a maximum difference of $48 \%$ between the high and low scenarios. The annual mineral waste production graph (Fig. 17b) is constructed through a derivation of the accumulative trend lines of mineral CDW generation (Fig. 17a) and shows an increasing trend independently on the scenario and a drop within the last decade of the century. Considering the predetermined projection scenarios, the largest CDW flow in the country is expected between 2060 and 2090 with a significant peak in the last 20 years of the considered time period. This surge is due to the larger volumes that are expected to be built with the increase of population, for example apartment blocks or larger housing units in this time period. By the end of the century, an average drop of $61.9 \%$ in the annual production is noticed in all three scenarios, due to the higher resilience of the newly built structures and the consideration that a large part of the future stock will result to be more rigid in terms of their demolition behaviour. Additionally, the fluctuations in the yearly generation of CDW are greatly influenced by the considered lifetime profiles (Fig. 12). Indeed, the drop observed after 2090 can be due to the slowdown of the lifetime curves than can be observed for buildings aged between 40 and 80 years (Fig. 12). This is a clear indication on the importance of the age analysis and the choice of suitable lifetime curves for the area in consideration.

\subsection{Feasibility of concrete recycling in areas with limited urbanization scale}

One of the largest uncertainties regarding recycling of mineral CDW in small geographical areas, such as Luxembourg, is related to the availability of the waste material flow. However, results show that the foreseen annual generation of $\mathrm{CDW}$ is comparable to that of other larger countries (Delvoie et al., 2019). In terms of the availability of the secondary raw materials, a ratio can be made between the expected mineral CDW arising from all considered scenarios and the expected concrete production in the next 80 years. This ratio will yield the theoretical

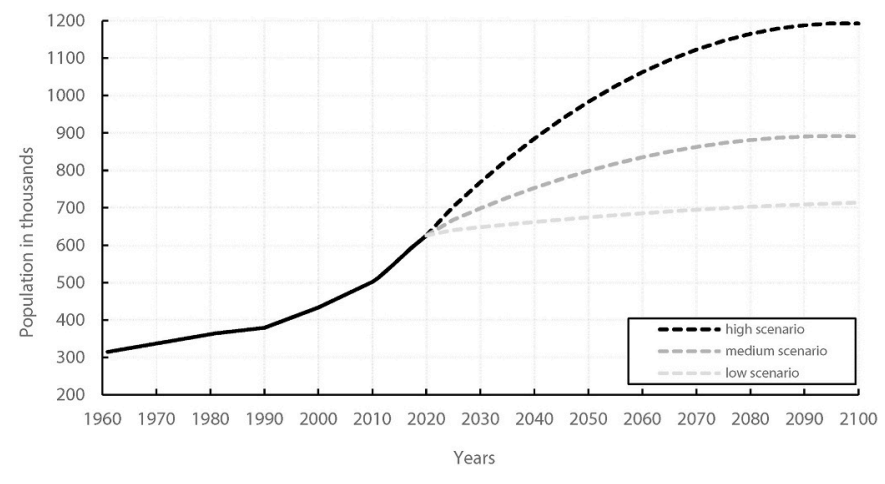

Fig. 16. Population evolution in Luxembourg and the considered future scenarios.
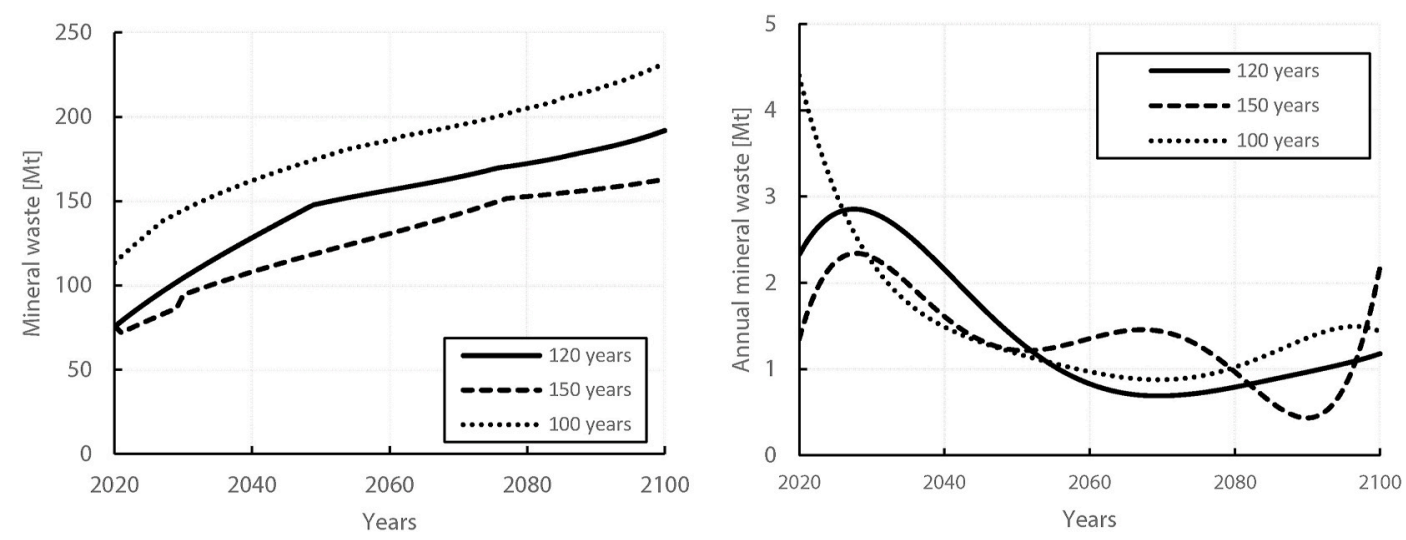

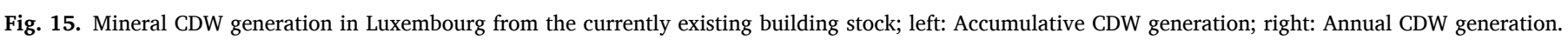



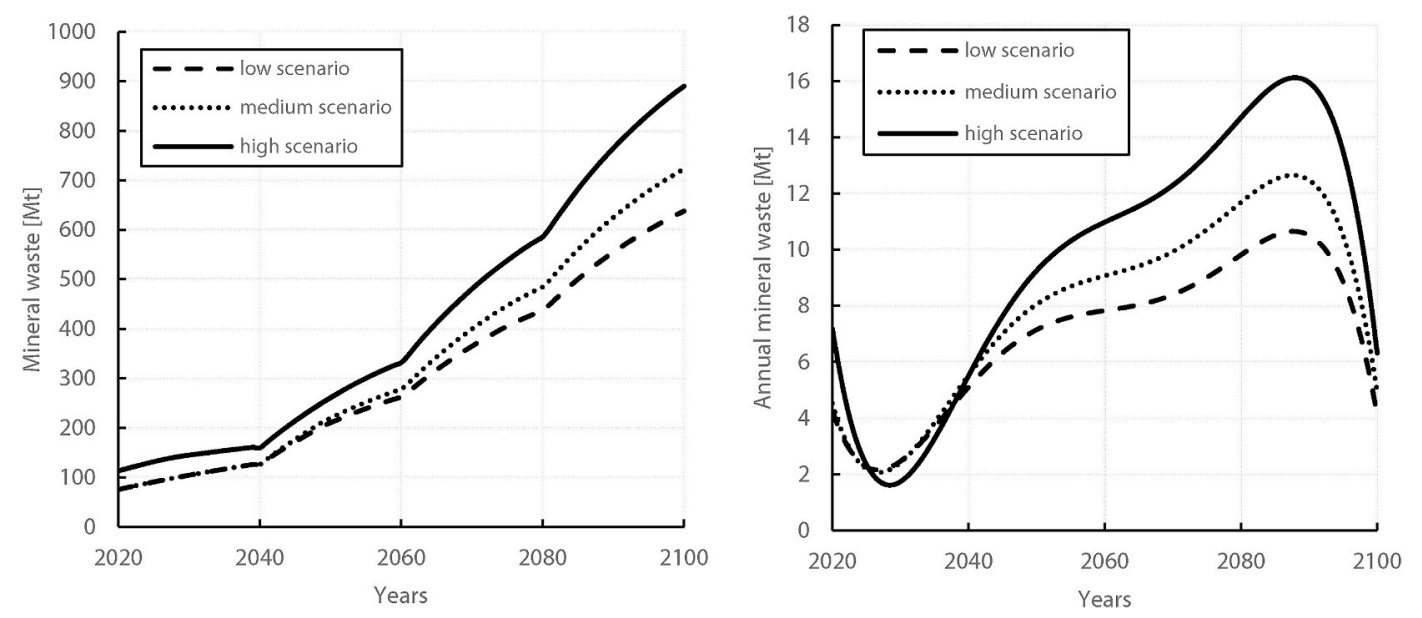

Fig. 17. Mineral CDW generation in Luxembourg from the future building stock; left: Accumulative CDW generation; right: Annual CDW generation.

possible substitution ratio strictly in terms of material quantity.

A normal distribution of the ratio between the generated mineral $\mathrm{CDW}$ and new concrete production allows to give an overview of the considered time period (Fig. 18). As it can be seen on Fig. 18a, for the majority of the studied period, the ratio is larger than 0.2 , which is currently the technical limit for use of recycled aggregates according to EN 12620 (BSI, 1262). If the demolition of future structures is considered Fig. 18b, the ratio remains higher than 0.2 , for the majority of the studied period. However, there is a larger probability of having shortage of recycled aggregates compared to the pervious case. As it can be noticed, the normal distribution of the existing building stock yields a more statistically rigid result, while the projected results demonstrate a higher variability. This is considered evident in this case based on the assumptions that were previously made in the data calculation, such as the population evolution, construction evolution, lifetime profiles, etc. On the other hand, it should be noted that other factors are to be considered in the CDW flow, such as different stakeholder engagement in the management of waste.

In terms of economic viability, the considered models also hint at concrete recycling as a cost-effective production for Luxembourg. The feasibility study of a concrete treatment plant with a capacity of $350 \mathrm{t} / \mathrm{h}$ (Coelho and De Brito, 2013) shows a break-even point in less than 3 years. If the lowest-case scenario is considered, namely considering only the current stock with a lifetime profile of 150 years, the flow of mineral $\mathrm{CDW}$ is calculated to be above $350 \mathrm{t} / \mathrm{h}$ for the majority of the considered timeframe (Fig. 19). However, further conditions will affect the viability of a concrete recycling plant. For example, it may be unrealistic to consider the entire generated $\mathrm{CDW}$ to be treated at the same plan. Even though this is a feasible scenario for small areas as Luxembourg in logistical terms, stakeholder engagement and market conditions are expected to further influence the management of CDW.

\section{Discussion}

The presented methodology shows the remarkable potential that a combination of geospatial evaluation, image analysis and material stock quantification can have on evaluating the dynamics of mineral CDW over the next 80 years. The findings indicated promising results not only in terms of evaluation of the building stock, but also as an outlook to promote concrete recycling and the circular economy of the construction sector, indicating that the potential generation of mineral CDW is suitable for an industrially and economically viable concrete production.

There is a limitation however in considering the entire demolished mineral construction to be recyclable material. The use of CDW as road backfilling will certainly continue to occur and, if this volume were to be recorded, the considered annual generations of mineral CDW will decrease. Furthermore, on-site use of demolished fraction will further reduce the availability of recyclable CDW. Also, these applications considerably influence the recorded volumes of waste, resulting in unreliable statistics. As shown in the results, there is a significant increase in mineral $\mathrm{CDW}$ if future constructions are considered, hinting at the

\section{Existing building stock}

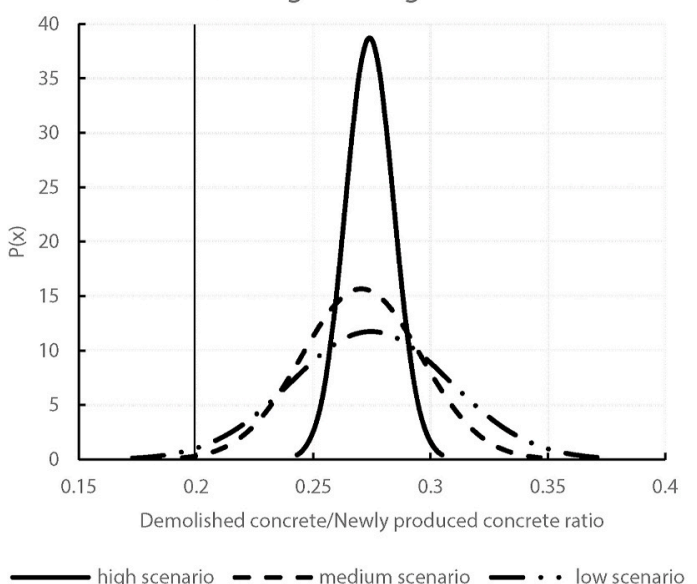

\section{Projected future building stock}

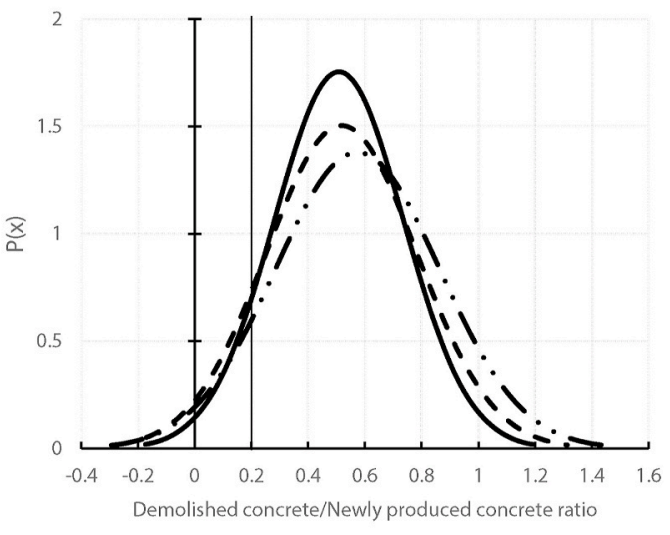

Fig. 18. Normal distribution of the (mineral CDW/new construction) rate for the considered scenarios. 


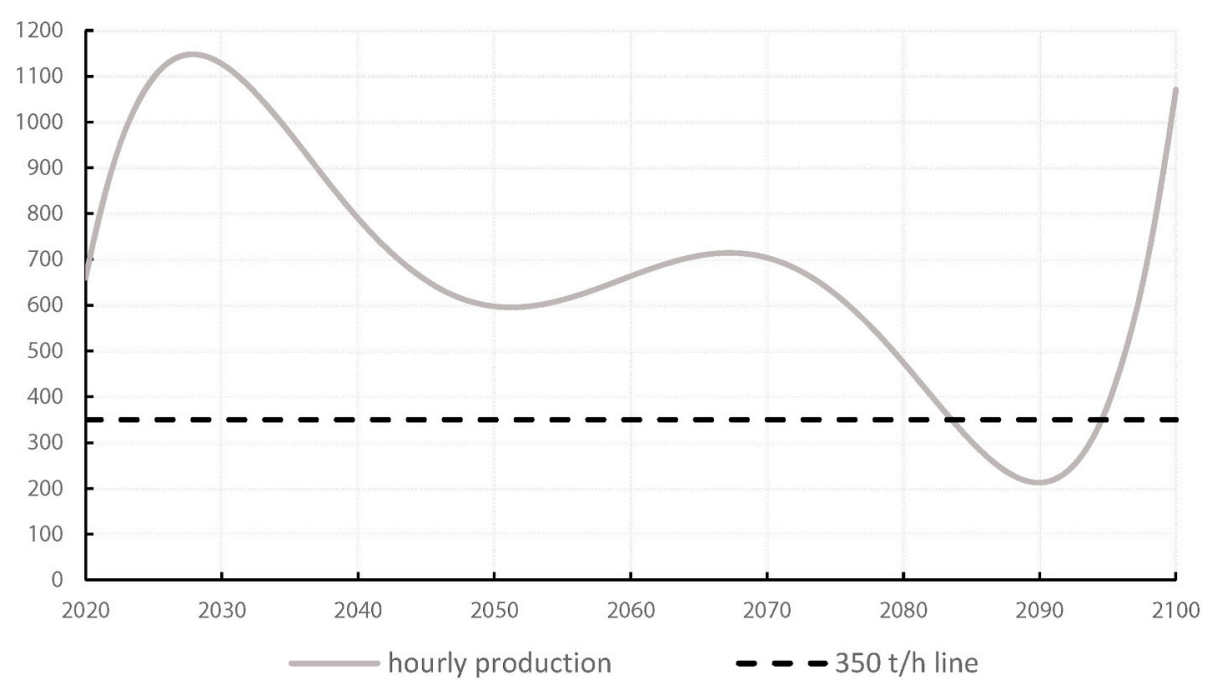

Fig. 19. Hourly mineral CDW generation for the lowest considered scenario.

importance of effective planning strategies that rely not simply on statistical recordings of accumulated waste, but rather on the realistic state of the art of the local CDW generation.

The evaluation of the building stock through image analysis offers a novice way of assessing the lifetime dynamics of the built environment. The importance of a geographical approach is key in this sense as the demolition behaviour is strictly tied to the socio-economic conditions of the area. Nevertheless, a few shortcomings were observed. The proposed methodology can be, at the moment, only considered globally for the intended purpose. The alternative local approach of considering all structures individually and assessing their characteristics is however unfeasible, since it is difficult to assess the realistic lifetime of a single building or a building type. The lifetime expectancy of individual structures includes significant ambiguities related to the socio-economic aspect of the region and it is not easily assessable without relying on assumptions that will increase the level of uncertainty. Therefore a normalization of the datapoints through a global regression is considered adequate for this purpose. Additional optimization can nevertheless be done through a case-study approach if the aim is to have a higher resolution (i.e., implementing the construction age into the local cadastre) and the proposed age-groups dynamics (Fig. 13) can be utilized if an age-specific analysis is required. The considerations of mathematical functions for the lifetime curves and the limitations set during the analysis can offer significant constraints as the analysed building stock does not exceed the maximum lifetime of the buildings. Error-free assumptions can only be made once a building stock is completely demolished, which, in this study, it is not the case. Therefore, it remains difficult to make evaluations on the accuracy of the data, especially when considering a large future timeframe. Furthermore, the lack of data records on the generation of CDW and the unregulated reuse of CDW on the demolition sites implies a further difficulty in assessing the affinity of the model.

Assessing the mineral material stock in each building through the presented model must be geographically adapted if such analysis is to be done in other areas. The proposed model is constructed for a NorthWestern built environment mainly based on concrete as structural material. Likewise, the considered coefficients are to be chosen based on the considered area. It must be stressed however that the considered model must be regarded as approximative and an exact analysis of the embedded materials can be done only through a case-study approach of the entire building stock.

\section{Conclusions}

A methodology to assess the amount of mineral CDW through material stock quantification and geospatial approaches was presented. This methodology was applied for the entire national building stock of Luxembourg to understand the typical volumes in small geographical areas and analyse the feasibility of concrete recycling based on the available volumes.

The proposed method allows for rapid analysis of large areas by relying solely on open-source data, thus avoiding extra costs and workload. By using image analysis of old cartography, a historic lifetime profile was extracted showing the demolition behaviour of buildings during the last 93 years, which rendered possible to extract the potential mineral CDW arising from the building stock through a consideration of stochastic scenarios for the next 80 years.

Results show that the $31.30 \%$ of the structures in Luxembourg are built before 1927, while the largest built gross volume is built after 1989. The total mineral materials embedded in construction in the country is $276.75 \mathrm{Mt}$, accounting for 450.817 tons/capita. Typical lifetime profiles extracted through image analysis show a mean service life of 122 years, although the survival behaviour depends on the period of construction and is not uniform for all the considered age groups. Based on the stochastic projections the mineral CDW generated from the existing building stock is expected to be up to $226.9 \mathrm{Mt}$ by 2100 , while if future building scenarios are considered, it can be as high as $885.3 \mathrm{Mt}$. The annual CDW production is expected to be sufficient for a viable concrete recycling activity if regulations on the waste volume flows are made available.

The described methodology offers a viable, flexible and rapid tool for management of the built environment, especially for planning of the best practices for treatment and re-use of waste arising from the construction sector.

\section{CRediT statement}

Lorenc Bogoviku: Conceptualization, Methodology, Validation, Formal analysis, Investigation, Resources, Data Curation, Writing Original Draft, Visualization. Danièle Waldmann: Conceptualization, Methodology, Validation, Resources, Writing - Review \& Editing, Supervision, Project administration, Funding acquisition.

\section{Declaration of competing interest}

The authors declare that they have no known competing financial 
interests or personal relationships that could have appeared to influence the work reported in this paper.

\section{Acknowledgements}

The authors express their gratitude towards companies Carrières Feidt, Cimalux, Cloos, ENECO Ingénieurs Conseils, Entrapaulus and Recyma for financing the project, as well as to Administration de l'Environment Luxembourg, Administration des Ponts et Chaussées Luxembourg and Service Géoportail for the technical support.

\section{References}

Administration du cadastre et de la topographie. La plate-forme de données luxembourgeoise - LiDAR 2019 [Online]. Available: https://data.public.lu/fr/data sets/lidar-2019-modele-numerique-de-la-surface-mns/. (Accessed 25 June 2020).

Administration du cadastre et de la topographie. La plate-forme de données luxembourgeoise [Online]. Available: https://data.public.lu/fr/organizations/ad ministration-du-cadastre-et-de-la-topographie/. (Accessed 25 June 2020).

Blengini, G.A., Garbarino, E., 2010. Resources and waste management in Turin (Italy): the role of recycled aggregates in the sustainable supply mix. J. Clean. Prod. 18 (10-11), 1021-1030.

Bogas, J.A., De Brito, J., Ramos, D., 2016. Freeze e thaw resistance of concrete produced with fi ne recycled concrete aggregates. J. Clean. Prod. 115, 294-306.

Book, S., 2018. Not on My Beach: the Great German Sand Shortage. Handelsblatt Today, 08-Mar.

Bradley, P.E., Kohler, N., 2007. Methodology for the survival analysis of urban building stocks. Build. Res. Inf. 35 (5), 529-542.

BSI, "EN 12620 - Aggregates for Concrete." .

Casali, S., 2012. "L'industrie sidérurgique luxembourgeoise depuis les années, vol. 60.

Coelho, A., De Brito, J., 2013. "Economic viability analysis of a construction and demolition waste recycling plant in Portugal e part I : location, materials, technology and economic analysis. J. Clean. Prod. 39, 338-352.

Corinaldesi, V., Letelier, V., Moriconi, G., 2011. "Behaviour of beam - column joints made of recycled-aggregate concrete under cyclic loading. Construct. Build. Mater. 25 (4), 1877-1882.

Deloitte, 2017. Document Information Resource Efficient Use of Mixed Wastes. no. October.

Delvoie, S., De Wallonie, S.P., Zhao, Z., 2019. Market Analysis of Recycled Sands and Aggregates in NorthWest Europe : Drivers and Barriers Market Analysis of Recycled Sands and Aggregates in NorthWest Europe : Drivers and Barriers. no. February.

European Construction Sector Observatory, 2017. European Construction Sector Observatory. no. June, vol. 27.

European Union. TABULA WebTool [Online]. Available: http://webtool. building-typology.eu/\#bm. (Accessed 25 June 2020).

European-Commission, "CDW: Material Recovery \& Backfilling."

European-Commission. Construction and demolition waste (CDW) [Online]. Available: https://ec.europa.eu/environment/waste/construction_demolition.htm. (Accessed 4 October 2019).

Gallardo, A., Carlos, M., Peris, M., Colomer, F.J., 2014. Methodology to design a municipal solid waste generation and composition map: a case study. Waste Manag. 34 (11), 1920-1931.

Gruen, A., Behnisch, M., Kohler, N., Gruen, A., Behnisch, M., Kohler, N., 2009. Perspectives in the reality-based generation, $\mathrm{nD}$ modelling, and operation of buildings and building stocks. Buiilding Res. Inf. 37 (5-6), 503-519.

Hardiman, S., 2018. Insight into Construction in Luxembourg by the European Construction Sector Observatory [Online]. Available: https://www.construction21. org/articles/h/insight-into-construction-in-luxembourg-by-the-european-constructi on-sector-observatory.html. (Accessed 25 June 2020).

Heinrich, M.A., Lang, W., 2019. Capture and Control of Material Flows and Stocks in Urban Residential Buildings.

Hiete, M., 2013. Waste management plants and technology for recycling construction and demolition (C\&D) waste: state-of-the-art and future challenges. In: Handbook of Recycled Concrete and Demolition Waste. Woodhead Publishing, pp. 53-75.

I. 59/SC 14, "ISO 15686-8:2008: Buildings and Constructed Assests - Service-Life Planning - Refernce Service Life and Service Life Estimation.”.

Jensen, J.R., Christensen, E.J., 1986. Solid and hazardous waste disposal site selection using digital geographic information system techniques. Sci. Total Environ. 56, 265-276 no. C.

Kameda, T., et al., 2014. Asbestos: use, bans and disease burden in Europe. Bull. World Health Organ. 92 (11), 790-797.
Kleemann, F., Lederer, J., Rechberger, H., Fellner, J., 2016. "GIS-based analysis of Vienna's material stock in buildings. J. Ind. Ecol. 1-13 vol. 00, no. 0.

Kleemann, F., Lederer, J., Rechberger, H., Fellner, J., 2017. GIS-based analysis of vienna's material stock in buildings. J. Ind. Ecol. 21 (2), 368-380.

Knaack, A.M., Kurama, Y.C., 2013. Design of Concrete Mixtures with Recycled Concrete Aggregates. no. 110.

Kohler, N., Hassler, U., 2002. The building stock as a research object. Build. Res. Inf. 30 (4), 37-41.

La Chambre de Commerce du Luxembourg, 2017. Luxembourg Economy: Open, Dynamic, Reliable [Online]. Available: https://www.luxinnovation.lu/wp-content /uploads/sites/3/2017/10/web_en_brochure_eco_lux_0917_cdc-1.pdf. (Accessed 25 June 2020).

Li, J., Ding, Z., Mi, X., Wang, J., 2013. A model for estimating construction waste generation index for building project in China. Resour. Conserv. Recycl. 74, 20-26.

Marie, I., Quiasrawi, H., 2012. Closed-loop recycling of recycled concrete aggregates. J. Clean. Prod. 37, 243-248.

Mastrucci, A., Baume, O., Stazi, F., Leopold, U., 2014. "Estimating energy savings for the residential building stock of an entire city : a GIS-based statistical downscaling approach applied to Rotterdam. Energy Build. 75, 358-367.

Mastrucci, A., Marvuglia, A., Popovici, E., Leopold, U., Benetto, E., 2017. Geospatial characterization of building material stocks for the life cycle assessment of end-oflife scenarios at the urban scale. Resour. Conserv. Recycl. 123, 54-66.

Menegaki, M., Damigos, D., 2018. A review on current situation and challenges of construction and demolition waste management. Curr. Opin. Green Sustain. Chem. $13,8-15$.

Omrane, M., Kenai, S., Kadri, E., Aït-mokhtar, A., 2017. Performance and durability of self compacting concrete using recycled concrete aggregates and natural pozzolan. J. Clean. Prod. 165, 415-430.

Ortlepp, R., Gruhler, K., Schiller, G., 2016. Material Stocks in Germany’s Non-domestic Buildings:a New Quantifcation Method, vol. 44, pp. 840-862 no. 8.

O'Connor, J., 2004. Survey on Actual Service Lives for North American Buildings. Woodframe Hous. Durab. Disaster Issues, no. October, pp. 1-9.

QGIS - A Free and Open Source Geographic Information System.”.

Reding, G., Flies, D., Trauffler, M., Sijaric, D., 2016. Implementation of the EPBD in Luxembourg [Online]. Available: https://epbd-ca.eu/ca-outcomes/outcomes-2015-2 018/book-2018/countries/luxembourg. (Accessed 25 June 2020).

Sadati, S., Arezoumandi, M., Khayat, K.H., Volz, J.S., 2016. Shear performance of reinforced concrete beams incorporating recycled concrete aggregate and highvolume fl y ash. J. Clean. Prod. 115, 284-293.

Salesa, Á., et al., 2017. "Physico - mechanical properties of multi - recycled concrete from precast concrete industry. J. Clean. Prod. 141, 248-255.

Sartori, I., et al., 2016. Towards Modelling of Construction, Renovation and Demolition Activities : Norway, s Dwelling Stock, towards Modelling of Construction, Renovation and Demolition Activities : Norway, s Dwelling Stock, $1900^{\wedge}$ 2100, vol. 3218, pp. 412-425 no. February.

STATEC. Le portail des statistiques Grand-Duché de Luxembourg [Online]. Available: htt ps://statistiques.public.lu/fr/acteurs/statec/index.html. (Accessed 25 June 2020).

The European Union Per Regulation, 2002. EN 1990 - Eurocode - Basis of Structural Design.

The Statistics Portal of Luxembourg, "Statec.lu." .

The Statistics Portal of Luxembourg. Indice des prix de la construction [Online]. Available: https://statistiques.public.lu/stat/ReportFolders/ReportFolder.aspx?IF LLanguage $=$ fra $\&$ MainTheme $=4 \&$ FldrName $=4 \&$ RFPath $=36$. (Accessed 25 June 2020).

Ulubeyli, S., Kazaz, A., Arslan, V., 2017. Construction and demolition waste recycling plants revisited: management issues. Procedia Eng. 172, 1190-1197.

UNEP, 2019. Sand and Sustainability: Finding New Solutions for Environmental Governance of Global Sand Resources. Geneva, Switzerland.

USEPA, 2016. Advancing Sustainable Materials Management: 2014 Fact Sheet. no. November. United States Environ. Prot. Agency, Off. L. Emerg. Manag., Washington, DC 20460, p. 22.

Villoria Sáez, P., Osmani, M., 2019. A diagnosis of construction and demolition waste generation and recovery practice in the European Union. J. Clean. Prod. 241.

Wu, Z., Yu, A.T.W., Shen, L., Liu, G., 2014. Quantifying construction and demolition waste: an analytical review. Waste Manag. 34 (9), 1683-1692.

Wu, H., Wang, J., Duan, H., Ouyang, L., Huang, W., Zuo, J., 2016. An innovative approach to managing demolition waste via GIS (geographic information system): a case study in Shenzhen city, China. J. Clean. Prod. 112, 494-503.

Yang, J., Du, Q., Bao, Y., 2011. Concrete with recycled concrete aggregate and crushed clay bricks. Construct. Build. Mater. 25 (4), 1935-1945.

Zonal statistics Plugin [Online]. Available: https://docs.qgis.org/2.18/en/docs/user_ma nual/plugins/plugins_zonal_statistics.html. (Accessed 20 August 2020). 